AROUEOLOGÍA Y SOCIEDAD № 28,2014 : $115^{-13} 6$

ISSN: 0254-8062

RECIBIDO: MARZO DE 2014

ACEPTADO: OCTUBRE DE 2014

\title{
HALLAZGO DE UNA PUERTA EN LA HUACA POTOSÍ, MARANGA
}

\author{
JOHNNY TAIRA CUSTODIO \\ UNIVERSIDAD NACIONAL FEDERICO VILLARREAL \\ jota_1891@hotmail.com \\ ARELÍ SULLCA ROLDÁN \\ UNIVERSIDAD NACIONAL FEDERICO VILLARREAL \\ areli1_5@hotmail.com
}

\section{RESUMEN}

El presente artículo trata sobre el hallazgo de una puerta arqueológica hallada durante las excavaciones del 2003 en el montículo 19 del complejo Potosí. Este montículo forma parte del complejo Maranga, valle bajo del Rímac. Consideramos importante el hallazgo de este elemento, ya que existen muy pocos especímenes (un ejemplo es la puerta de Pachacamac), y puede brindarnos datos importantes para explicar el uso de las puertas en el complejo Maranga. La puerta estaba asociada a un pasadizo de adobitos, que conducía a un recinto cuadrangular pintado de ocre-amarillo; al parecer, la puerta es parte de un rito de sellamiento, con incineración y enterramiento de estructura. En el presente artículo se brinda el resultado de los análisis que efectuamos, así como la interpretación de una posible función arquitectónica y social, de las puertas durante las fases finales de la cultura Lima (Maranga).

PalabRas Clave: Huaca Potosí, Cultura Lima, Maranga, Puerta prehispánica, Periodo Intermedio Temprano, Periodo Horizonte Medio.

\begin{abstract}
This article is about the archaeological discovery of a door found during the 2003 excavations in the mound complex 19 Potosi, this mound is part of the Maranga, under the Rimac valley. Consider important to the discovery of this element, as there are very few specimens (an example is the door of Pachacamac), and can give us important data to explain the use of the doors in the complex Maranga. The door was associated with a adobitos passageway that led to a quadrangular enclosure painted ocher-yellow, apparently, the door is part of a rite of sealing, with burning and burial of structure. In the present article provides the results of the analysis we perform, as well as a possible interpretation of architectural and social function of the doors during the final stages of the Lima culture (Maranga).
\end{abstract}

KEYwords: Huaca Potosi, Lima Culture, Maranga, Door Prehispanic, Early Intermediate period, Middle Horizon period. 


\section{INTRODUCCIÓN}

En el año 2003 se llevó a cabo el Proyecto de Investigación Arqueológica «Excavación con fines de consolidación, conservación, mantenimiento y Puesta en Valor en el Complejo Arqueológico Pando: Potosí, Miguel Grau, Aramburu. Distrito de San Miguel, Provincia de Lima», proyecto financiado por el Programa A Trabajar Urbano del Ministerio de Trabajo y Promoción del Empleo, con el auspicio como Organismo proponente de la ONG Hermana Tierra y el apoyo técnico logístico del Museo de Arqueología y Antropología de la Universidad Nacional Federico Villarreal, el apoyo del Museo Arqueológico Josefina Ramos de Cox del Instituto Riva-Agüero de la Pontificia Universidad Católica del Perú y con la aprobación y supervisión permanente del entonces Instituto Nacional de Cultura.

El sitio arqueológico Potosí o Montículo 19 pertenece al Complejo Arqueológico Maranga, ubicado en la margen izquierda del valle bajo del río Rímac y a muy pocos kilómetros del litoral. El sitio tiene una posible filiación cultural que va desde el Intermedio Temprano (500 a.C.- 700 d.C.), que funcionaba como centro administrativo y ceremonial, hasta el Intermedio Tardío (1000- 1400 d.C.), momento en el que fue usado como cementerio.

Durante las excavaciones se encontró una puerta asociada a un recinto cuadrangular pintado de color amarillo, esta puerta se conservaba en un muy buen estado, incluso los troncos laterales que lo sostenían se encontraban in situ. Este hallazgo llamó mucho la atención pues solo se tenía reportes de la existencia de muy pocas puertas prehispánicas, hasta el momento el único hallazgo de una puerta para la costa central estaba referido a la famosa puerta de Pachacamac, encontrada por Giesecke en 1938 durante una limpieza en el templo viejo.

La mayoría de hallazgos referido a puertas, se encuentran definidos por el descubrimiento de bases o improntas que hacen suponer que existió una posible puerta como en los casos de huaca Pucllana y San Marcos (Flores 2005; Lumbreras 2011). Estas evidencias negativas nos indican la importancia de las puertas para lugares públicos o religiosos, que servían principalmente como un elemento separador y de «protección» entre lo profano y lo sagrado, entre lo público y privado, es decir, para separar y resguardar objetos o personas con mucho poder social y simbólico, impidiendo el pase libre hacia él, o restringiendo la visibilidad de los visitantes.

Para realizar el análisis de la puerta de Potosí se realizó un trabajo arqueográfico, constatando con los datos de campo y sus asociaciones para así poder determinar una posible función y cronología. Debido a la poca cantidad de evidencias arqueológicas reportadas hasta el momento, es un poco complicado y difícil poder generalizar o definir el uso de las puertas en el mundo prehispánico, sin embargo, con el análisis realizado trataremos de plantear una función, no solo estructural, sino social dentro del mundo prehispánico.

\section{Investigaciones en Maranga y huaca Potosí}

El valle del río Rímac fue uno de los escenarios principales de la costa central que presentó una densa demografía y diferentes procesos sociales, es aquí donde se desarrolló la población que habitó el complejo arqueológico Maranga, denominado así a la cultura desarrollada antes del imperio Wari. Este se encuentra ubicado en la margen izquierda del río Rímac, a tres kilómetros del litoral, lo que conllevó que fuera una sociedad dedicada a la pesca y al culto al mar, evidencia que se encuentra plasmada en su iconografía, tanto en cerámica, textil y demás manifestaciones culturales materiales. El complejo Maranga-Chayavilca (Canziani 1987; 2009) se encuentra conformado por una serie de montículos, algunos de ellos pirámides escalonadas, que datan del periodo Intermedio Temprano, hasta el Horizonte Tardío (Fig. 1), perteneciendo la mayoría de los edificios monumentales al Intermedio Temprano. El desarrollo y crecimiento urbano desordenado moderno ha afectado a muchos de estos montículos, llegando a seccionarlos e incluso a desaparecerlos. 


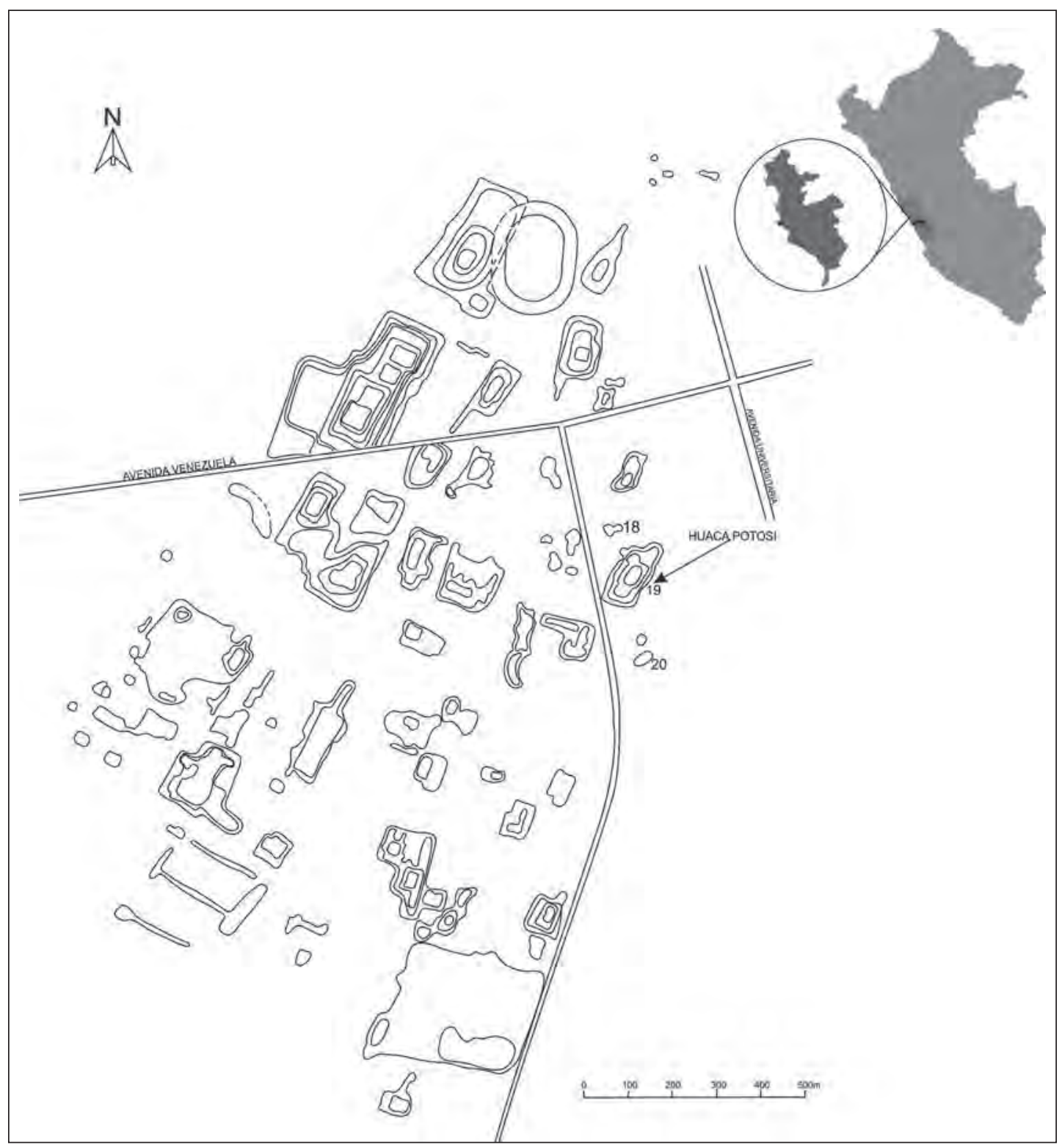

Figura 1. Plano del complejo arqueológico Maranga. Las líneas punteadas indican las secciones desaparecidas (Espinoza 2010: 266).

Los primeros reportes científicos sobre Maranga se dieron desde la segunda mitad del siglo XIX, viajeros como Ephraim Squier (1974), Thomas Hutchinson (1873) y Ernst Middendorf (1972) realizaron reportes sobre estos montículos, especialmente este último, ya que gracias a él se tiene las primeras descripciones detalladas, así como gráficos y fotografías del complejo Maranga. Este investigador identificó sectores urbanísticos, llamándole mucho la atención un sector amurallado que considera como el centro de la urbe. Posteriormente investigadores como Uhle, quien nombra como Proto-lima a esta cultura, Villar Córdoba (1935) y Tello (1999), realizan pequeñas investigaciones en el complejo, en el caso de Villar Córdoba, analiza las toponimias y nombres de los sitios, un posible origen Aymara. 
Tello hace un registro del complejo, describe algunos montículos como huaca La Concha, cinco cerros (Mateo Salado), Aramburú, entre otros, llega a tomar fotos y dibujar planos de algunos sectores. Logra identificar murallas, caminos y tres barrios, denominando a toda esta zona como Watika-marka.

Alfred Kroeber y Jacinto Jijón y Caamaño, son los primeros en intervenir el Complejo Maranga, llevando a cabo excavaciones y planteando teorías sobre las costumbres y demás manifestaciones de la población que habitaba. En 1925 Kroeber realizó excavaciones en las huacas Middendorf y San Marcos, practicando numerosos cortes exploratorios y trincheras, sin embargo no llegó a publicar sus resultados hasta muchos años después. Propone que los montículos correspondían a un periodo anterior a una supuesta expansión Tiahuanaco y correspondería al Proto-Lima planteado por Uhle (Kroeber 1954).

Por otro lado Jijón y Caamaño realizó excavaciones en las huacas San Marcos, Concha y Middendorf, en el mismo año que Kroeber, descubriendo numerosos entierros humanos, así como piezas de cerámica de diverso tipo asociados a las tumbas y rellenos arquitectónicos; entre sus hallazgos llama la atención el descubrimiento de una balsa de totora de unos siete metros aproximadamente. Propone que los montículos corresponden a la cultura Proto-Lima y se encontraba constituido por una aristocracia guerrera que había llegado al valle, conquistando e imponiéndose a los pobladores originales. Los hallazgos de huesos trabajados, entierros incompletos y mutilados hizo que se planteara que la sociedad lima era un pueblo sanguinario que practicaba ritos sangrientos y crueles (Jijón y Caamaño 1949).

Posteriormente muchas fueron las investigaciones en el complejo (Jaime 1999; Narváez 1999; Shady y Narváez 1999, 2000; Mack Kay y Santa Cruz 2000; Fung 2004: 297-308), de los ellos resaltan las de Pedro Alarcón, quien planteó la secuencia constructiva Lima basándose en las excavaciones realizadas en la huaca San Marcos (Alarcón 1971) y la de José Canziani, que realizó un estudio de la disposición urbana de los sectores Maranga (Canziani 1987). Sin embargo, los principales y mayores aportes, por su constante investigación, son del Patronato del Parque de las Leyendas y su museo de sitio Ernst Middendorf, aquí se encuentra la mayoría de montículos del complejo Maranga (Carrión y Espinoza 2007a, 2007b; Manrique 2011, 2012).

Las investigaciones etnohistóricas no son ajenas al Complejo Maranga, María Rostworowski establece la existencia del señorío de Maranga al estudiar el Cuaderno de Visita de 1549, en este manuscrito se menciona la existencia de este curacazgo, que estaba dirigida por Juan Chayavilca, curaca de dicha región. Los visitadores mencionan que los pobladores tenían acceso a los recursos del mar y realizaban intercambio con otros señoríos como yauyos y colli; sobre el origen de la población se menciona que es posible que sean mitmaq norteños traídos hasta el lugar debido a una sublevación del Chimucapac hacia el imperio Inca (Rostworowski 1978: 88-97).

El montículo 18 es un pequeño promontorio sin estructuras visibles en su superficie, presenta una forma irregular debido a las múltiples mutilaciones sufridas durante la urbanización de la zona. Tiene aproximadamente $2 \mathrm{~m}$ de altura y alrededor de $700 \mathrm{~m}$ de extensión. La primeras investigaciones en este montículo se llevó a cabo en la década de 1970, por la arqueóloga Martha Belcore (Belcore 1970), de este trabajo no existe mucha información disponible, solamente se resalta el hallazgo de una figurina de $40 \mathrm{~cm}$ de altura, que representa a un personaje con los brazos extendidos. Esta figurina de filiación Chancay tiene la particularidad de presentar una cocción en atmósfera reducida. Presumiblemente habría sido hallado en la parte superior del montículo, es decir de las estructuras asociadas a la segunda etapa constructiva, la cual se presume del periodo Intermedio Tardío.

En la campaña de excavación del 2003 se pudo determinar que existieron cuatro fases de ocupación que va desde el Intermedio Temprano, hasta el Intermedio Tardío, cada una de estas fases presentan un patrón constructivo propio (Figs. 2 y 3). La primera fase está representada por muros hechos con adobitos unidos con barro y usando la técnica «del librero», esta fase pertenece a la cultura Lima; la segunda se encuentra representada por muros hechos en base a cantos rodados unidos con barro, que formaban lo que parece ser una plaza; por último, la tercera fase corresponde a la 
construcción de estructuras circulares y cuadrangulares, denominadas cámaras y se encuentran ubicadas en la parte superior del montículo, por último, la cuarta fase corresponde a cistas ubicadas en el extremo suroeste del montículo, poseen forma cuadrangular y están hechas con adobe, esta última fase correspondería al Intermedio tardío y se está usando como cementerio (Ccachura 2010).

El sitio arqueológico Potosí (montículo 19) está compuesto por tres plataformas o niveles, con una altura de $9 \mathrm{~m}$ y un largo máximo de $100 \mathrm{~m}$. Este montículo se asocia a un conjunto de estructuras pequeñas hechas de adobitos que se ubican en el lado norte y presenta una orientación hacia el noreste.

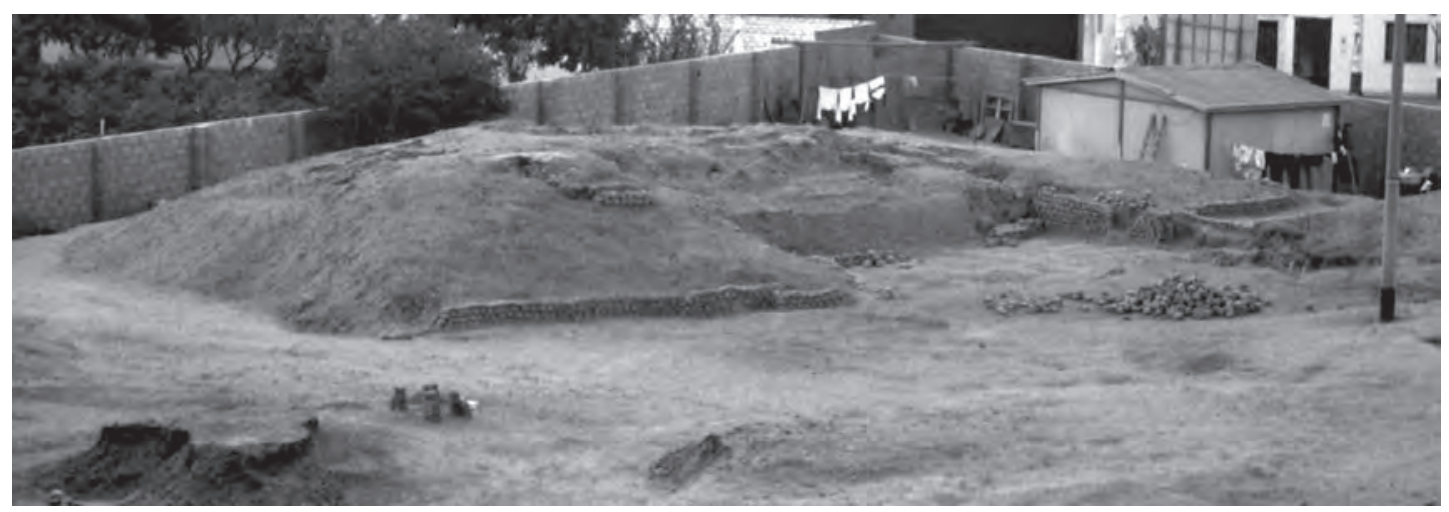

Figura 2. Vista general del montículo 18.

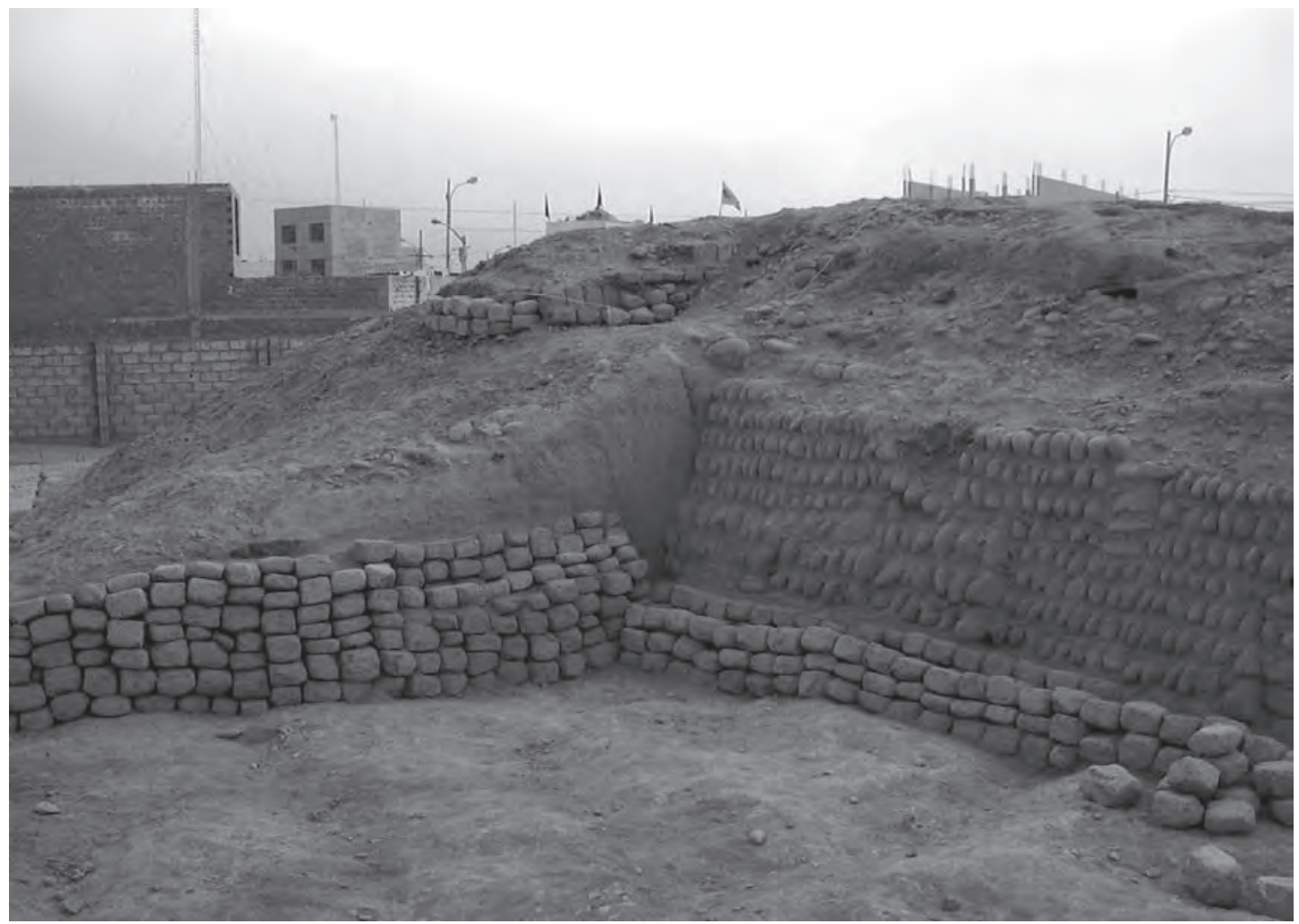

Figura 3. Area excavada del monticulo 18, se aprecia el muro de la fase 2. 
La primera intervención arqueológica en el sitio se llevó a cabo en el año de 1990 y 1991 por la arqueóloga Sonia Quiroz, quién realizó excavaciones de prospección en el montículo principal (Montículo 19 o Potosí), siendo el objetivo principal de su excavación era definir la secuencia cultural interna (Quiroz 1992), es así que se seleccionó dos sectores (I y II) de los cuales pudo identificar ocupación Lima y republicana en el sector I, mientras que en el sector II (Fig. 4) encontró estructuras hechas con adobitos paralelepípedos y cuadrangulares, construidos con la «técnica a» (arreglo de muros de adobes en soga y en dos filas) planteada por Alarcón (1971), definiendo que estas estructuras pertenecen a la última fase de la cultura Lima.

En las investigaciones llevadas a cabo en 2003 se excavó las tres plataformas, con dicha intervención se pudo definir que en la plataforma 2 sur existen tres momentos de ocupación, el primero está relacionado con un piso que al parecer cubría gran parte de la plataforma. En un segundo momento se llevó a cabo remodelaciones con construcción de recintos y pasajes ejecutados sobre el piso, relacionado posiblemente a la ocupación Lima Tardío, luego el corredor construido sobre el piso de la plataforma y el recinto con muros de tapial (excavado por Sonia Quiroz en 1991) es la

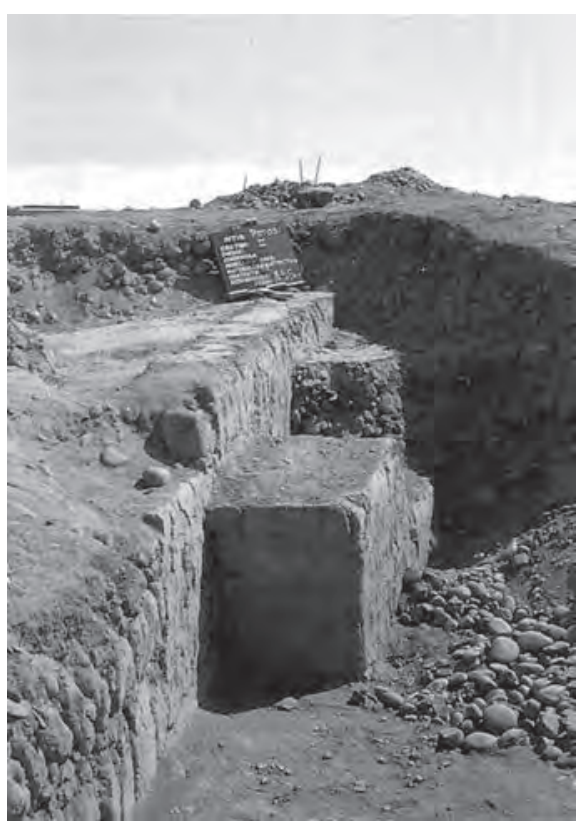

Figura 4. Excavaciones del sector II en huaca Potosí en 1991 (Quiroz 1992: 143). tercera y última ocupación (Fig. 5).

En la plataforma 2 norte se encontró una serie de remodelaciones, tanto en la arquitectura como en el manejo del espacio, muchas de los recintos fueron reutilizados como cementerio. Se halló varios entierros, que pertenecerían a las últimas fases del Horizonte Medio e inicios del Intermedio Tardío, muy posiblemente al Ychsma Medio.

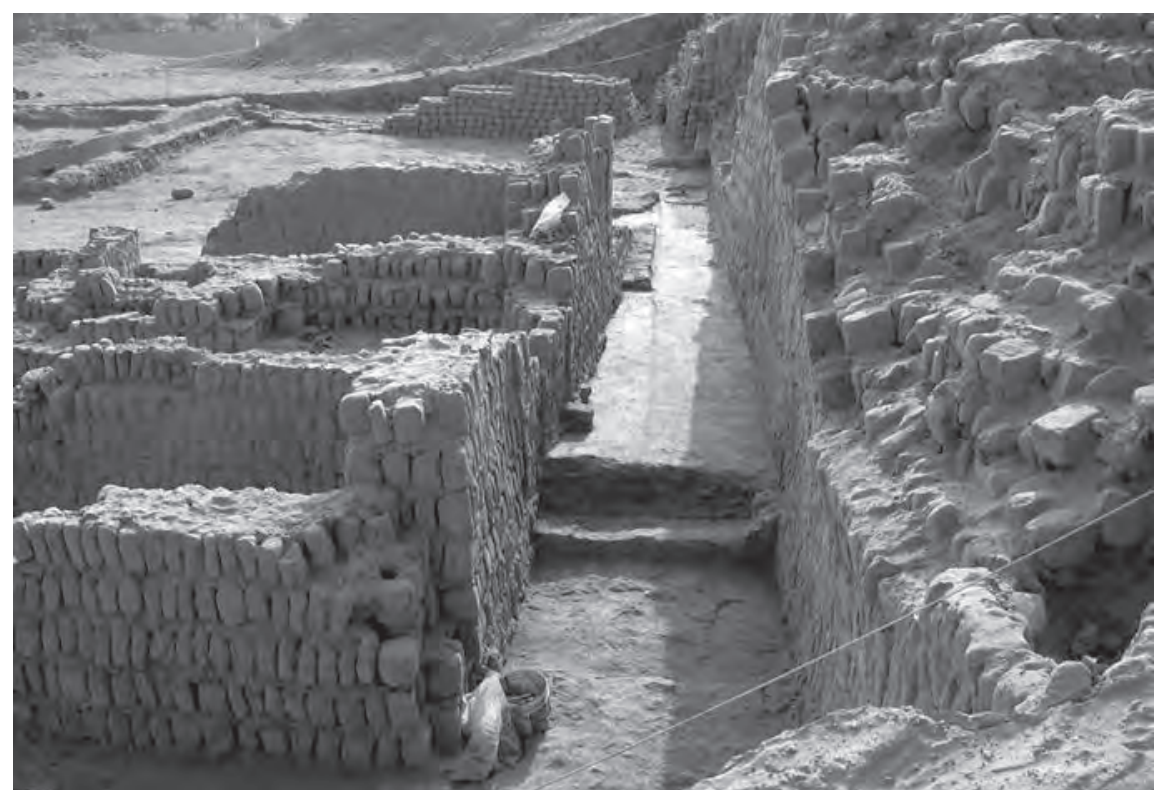

Figura 5. Excavación de la Plataforma 2 sur. 
En la plataforma 3 se puede distinguir cuatro secuencias de ocupación con sus respectivas remodelaciones. Aquí se halló un corredor delimitado con muros pintados de color ocre, este corredor presenta una rampa que va de sureste a noreste. Para el caso de los elementos arquitectónicos en este nivel, se encontró dos fases constructivas, la primera corresponde a un cuidadoso planeamiento en la construcción de los muros, mientras que en la segunda se nota el uso de adobitos reutilizados y construcciones apresuradas, es posible que estas fases correspondan a las ultimas ocupaciones del sitio.

En conclusión, con las excavaciones realizadas se puede decir que huaca Potosí presenta una ocupación que data desde el Intermedio Temprano hasta el Intermedio Tardío. En el primer periodo se está utilizando este montículo como un lugar administrativo y religioso, caracterizado por las construcciones de muros de adobitos; durante el Horizonte Medio se clausuran accesos con ritos como el de depositar perros atados y romper grandes cantaros, este periodo está dado por la invasión Wari en la costa central. Por último, durante el Intermedio Tardío el sitio está siendo usado como cementerio Ychsma (Gabe 2004).

\section{EL CONTEXTO DE LA PUERTA}

La puerta se halló en la plataforma 3 del montículo 19, bajo una capa de tierra suelta, fragmentos de argamasa de barro y abundantes adobitos caídos. Esta puerta se encontraba en casi un perfecto estado de conservación y colocada en la 1 posición original donde era utilizada (Fig. 6). Se halló también los troncos donde se encontraba emplazada la puerta cuando estaba en funcionamiento (Figs. 7 y 8), sin embargo estos troncos, así como parte de la puerta se encontraba quemada, esto posiblemente se debió a un ritual de clausura, ya que el recinto a donde se accedía por medio de la puerta se encontraba tapado con adobitos dispuestos ordenadamente, también se encontró, en el corredor donde estaba la puerta, un delgado lente de tierra y adobes quemados, al igual que ofrendas consistentes en un plato con restos orgánicos y una botella decorada con motivos lineales, geométricos y zoomorfos. La primera cerámica fue colocada en el piso junto a la puerta, en una esquina de los muros, mientras que la botella se encontraba debajo de la puerta, junto a uno de los postes.

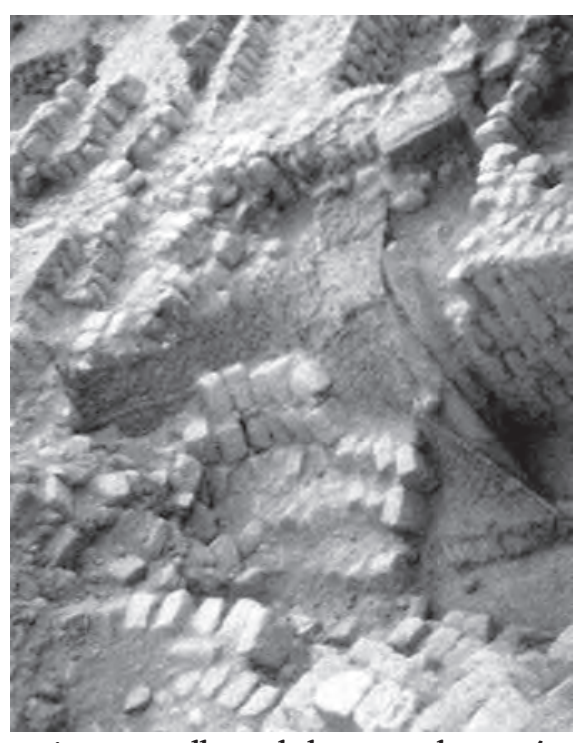

Figura 6. Hallazgo de la puerta de Potosí.

\section{ANÁLISIS DE LA PUERTA}

Para el estudio de la puerta de Potosí se usó los procedimientos metodológicos requeridos en toda investigación arqueológica, para esto se describió el material de estudio lo más objetivamente posible, usando un registro fotográfico y de fichas, en donde se encuentra detallado todos los componentes y técnicas usadas para la elaboración de la puerta; se tomó pequeñas muestras de la fibra vegetal, así como de cada uno de los componentes para un análisis biológico que conlleve a la identificación botánica de los elementos.

Posteriormente se llevó a cabo el análisis crítico del objeto, para poder determinar cronología, funcionalidad estructural y social; con esto se pretende buscar el contexto histórico y social en la que existió la puerta de Potosí.

La puerta de Potosí mide alrededor de 1,92 x 1,78 cm, con un grosor de unos $3 \mathrm{~cm}$ en el cuerpo. Se encuentra compuesta por un total de 75 troncos de carrizo (Ammophila arenaria sp.), que miden 1,95 


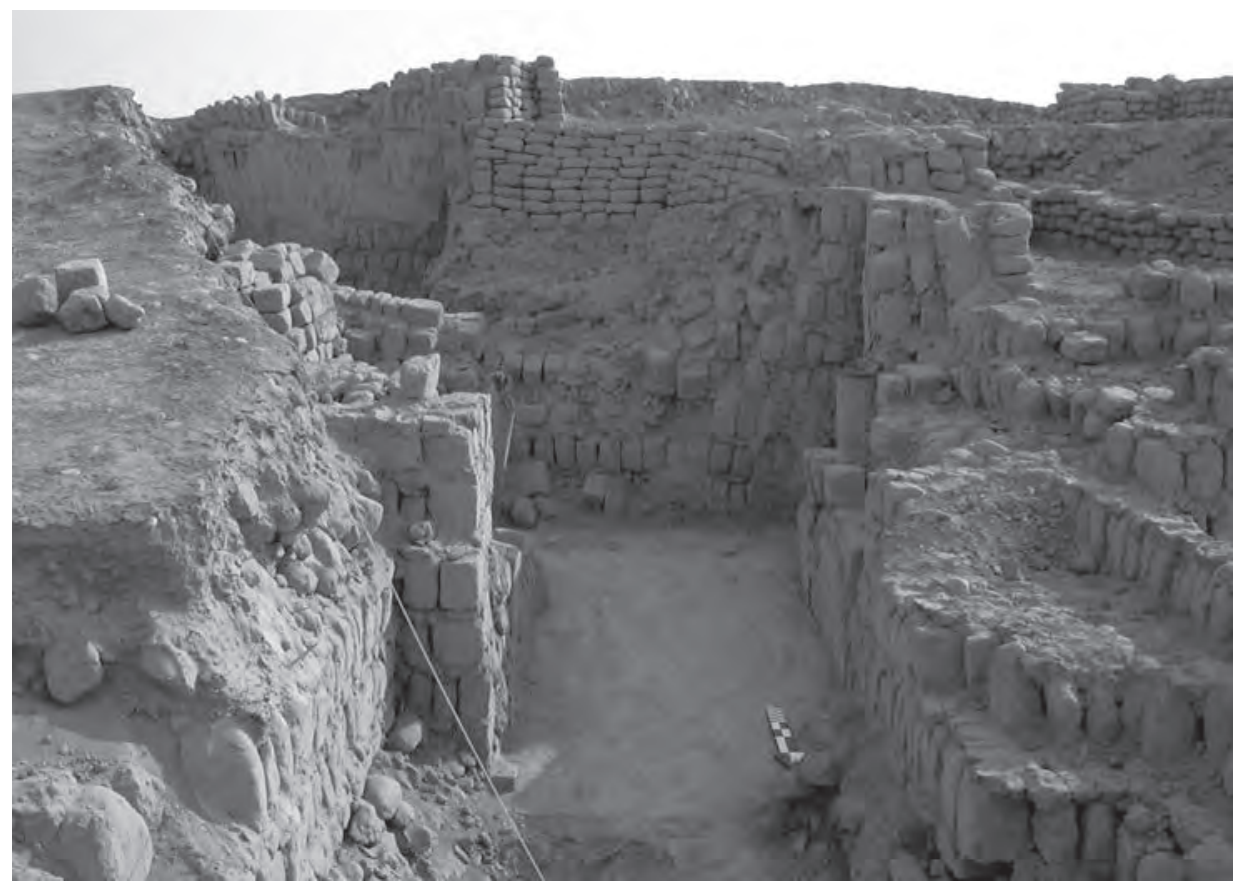

Figura 7. Entrada al recinto clausurado, se puede notar los troncos, donde estaba emplazada a la puerta, a los costados.

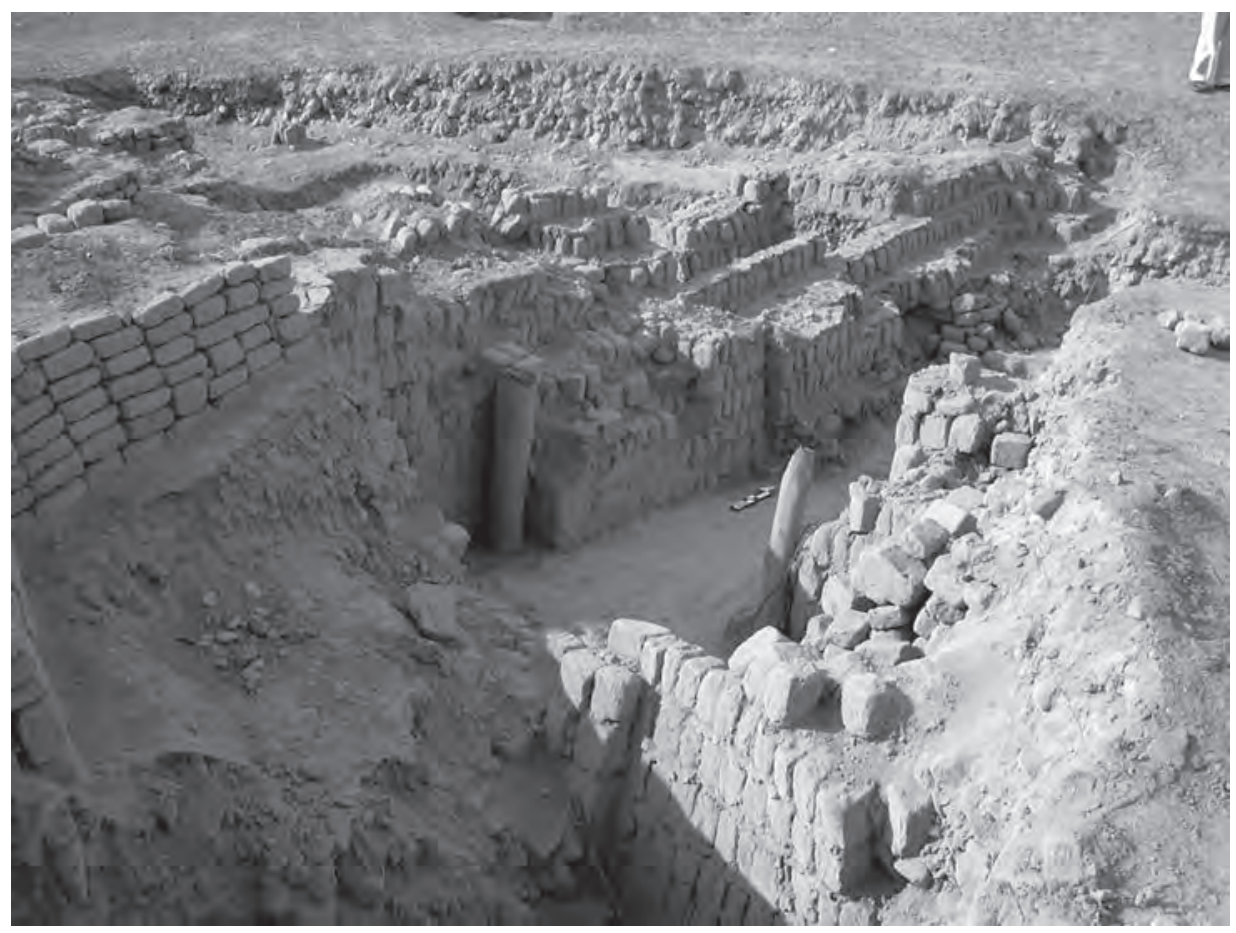

Figura 8. Vista posterior de la entrada al recinto clausurado, se puede notar los troncos donde estaba emplazada la puerta, así como el pasadizo por donde se accedía. 
$\mathrm{cm}$ de largo por $2 \mathrm{~cm}$ de ancho, de estos carrizos once se encuentran partidos y miden en promedio 70 $\mathrm{cm}$ de largo; estos forman la estructura de la puerta. Estos se encuentran unidos entre sí por medio de cuerdas hechas con junco (Scirpus sp.), esta unión se hace mediante un proceso de «tejido o trenzado» entre las cuerdas y los dichos carrizos, a su vez, estas cuerdas amarran y sujetan seis troncos, de un árbol que no pudimos identificar, cinco de los cuales aún se conservan fragmentados.

La cuerda usada en la puerta merece una especial atención, ya que al analizarla nos dio una gran cantidad de datos tanto cuantitativo, como cualitativo que expondremos posteriormente. Esta presenta una torsión y retorsión en «Z», a excepción de un sector de la puerta que presenta una torsión y retorsión en «S». La presencia de nudos (Fig. 9) nos indica que se están fabricando varias cuerdas pequeñas que luego son unidas entre sí para formar una cuerda larga que se está utilizando para «trenzar» la puerta, en total se contabilizaron 57 nudos, lo que daría un total de 58 cuerdas estaría siendo utilizadas. La puerta presenta evidencia de haber sido reparada, este proceso consistió en ajustar las varas de carrizo para sellar los espacios dejados por los carrizos faltantes.

Se realizaron estudios en cuanto a la cantidad y metraje de cuerda utilizada, lo que nos dio como resultado que se estarían usando, como ya se mencionó, 58 cuerdas de 7,60 m cada una, esto en total nos da unos 444,40 m de cuerda, a la que llamaremos preparada, por presentar retorsión y ser la que se está usando para el trenzado; mientras que la cuerda semipreparada, es decir la cuerda solo con torsión, estaría midiendo $888,80 \mathrm{~m}$. Para un mejor análisis y descripción se ha dividido a la puerta

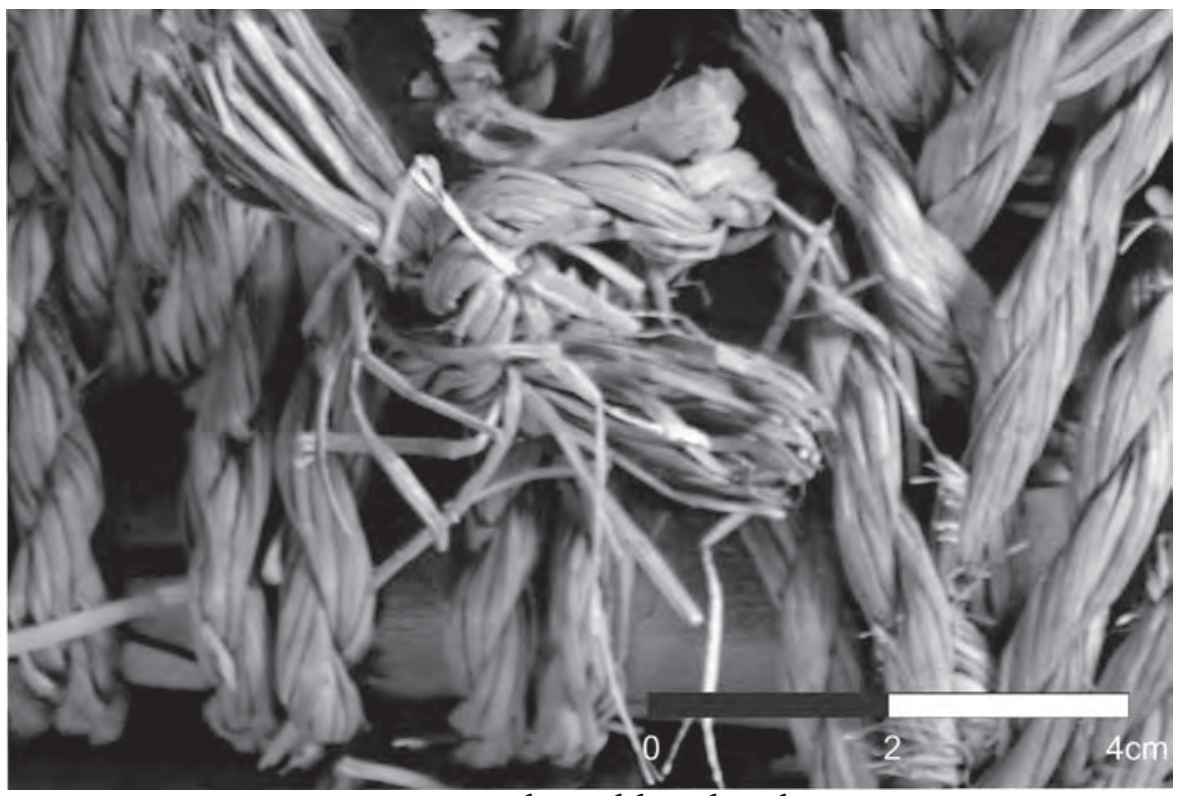

Figura 9. Evidencia del uso de nudos.

en dos lados, siendo el lado 1 la que presenta solo el trenzado (Fig. 10) y la lado 2 la que presenta los troncos (Fig. 11), a su vez estos lados se subdividieron en cuatro zonas a la que dominaremos A1, A2, B1, B2, C1, C2, D1 y D2, correspondiéndoles la numeración de acuerdo al lado que pertenezcan (Figs. 12 y 13$)$.

Se ha podido identificar tres tipos de técnicas de tejido que están siendo usadas en la elaboración de la puerta, estas son:

- Técnica 1: Consiste en un trenzado donde la cuerda pasa en forma diagonal hacia la izquierda y derecha (una dirección por turno), agarrando tres carrizos por vez antes de meterse por debajo del tercero de estos. En el anverso de la puerta, es decir en el lado 2, la cuerda proveniente del 

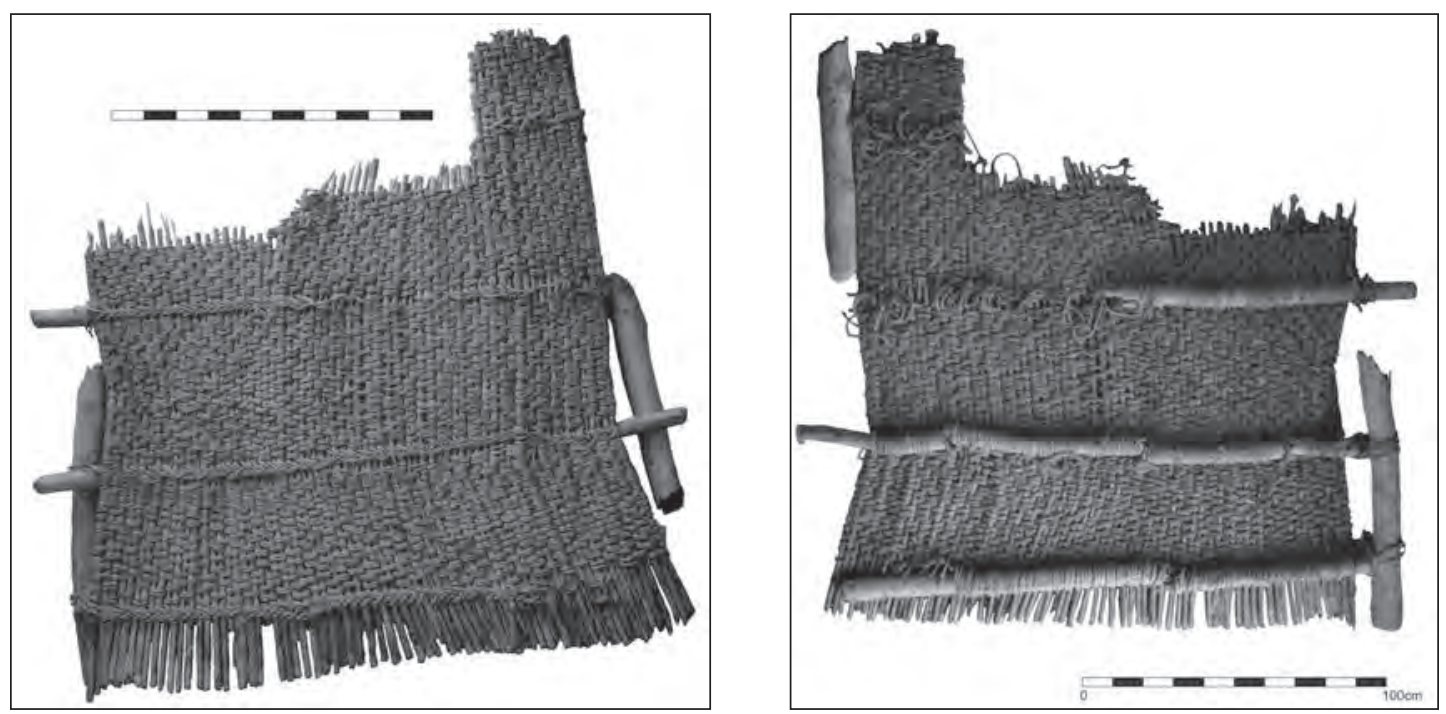

Figuras 10 y 11. Vista general de los lados 1 y 2 de la puerta de Potosí.
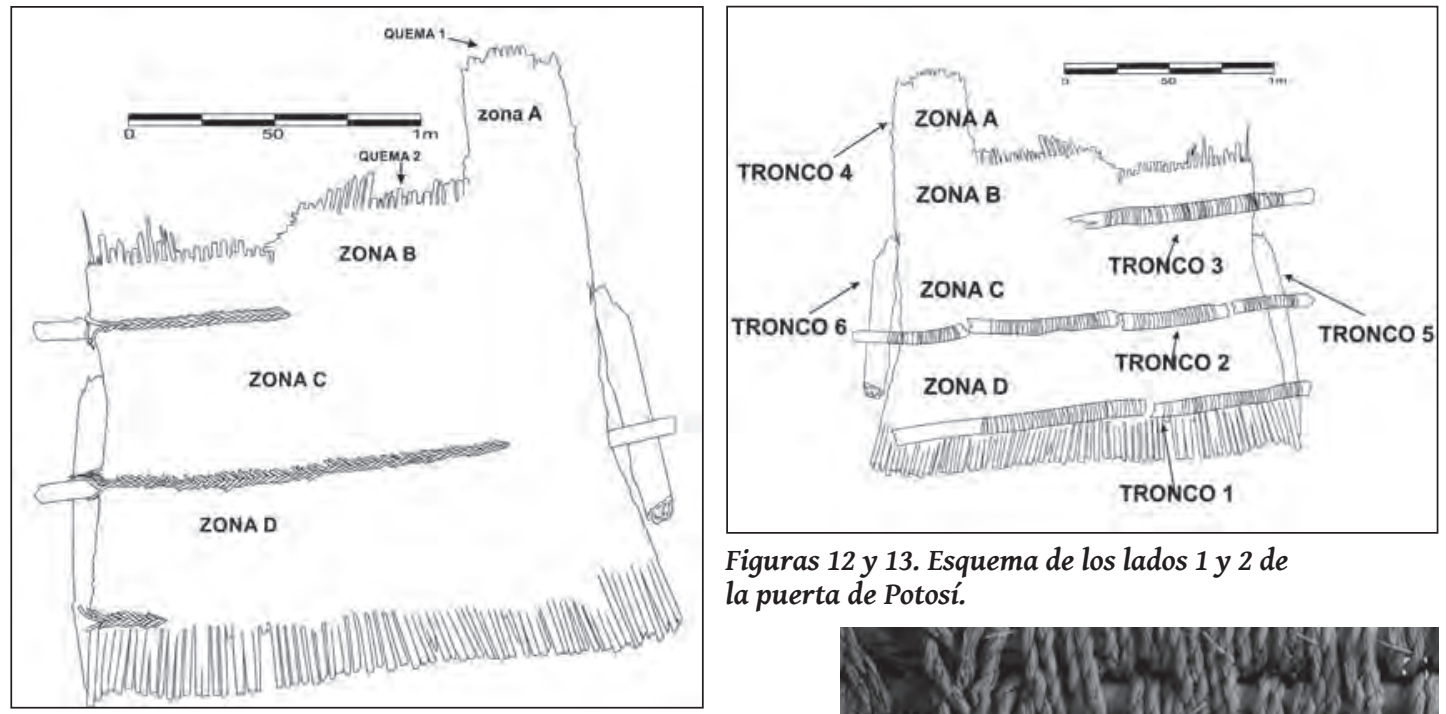

Figuras 12 y 13. Esquema de los lados 1 y 2 de la puerta de Potosí.

tercer carrizo envuelve al tronco que sirve como soporte del cuerpo y se introduce por entre los carrizos para volver a salir por el lado 1 , y repetir la misma secuencia (Fig. 14).

Este trenzado une los troncos del lado 2 con el cuerpo de carrizo, y da un aspecto de diseño en forma de «V». Hemos considerado esta técnica como separador de las zonas (A, B, C, D).

- Técnica 2: Consiste en un trenzado donde la cuerda agarra 2 troncos de carrizo por vez, antes de meterse por el segundo y repetir la misma acción por el

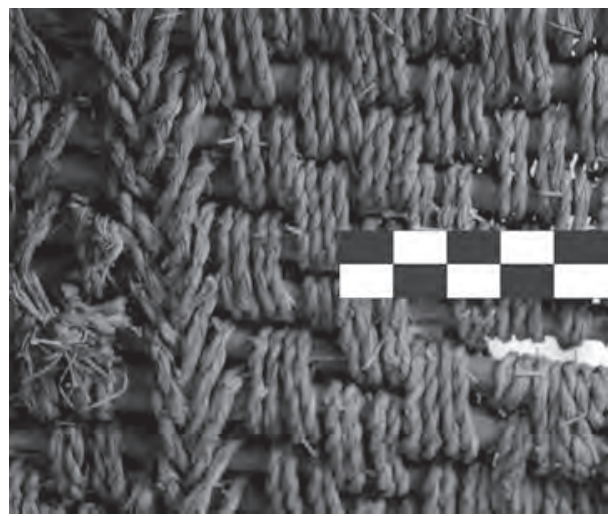

Figura 14. Técnica 1, se puede notar el acabado en forma de "V". 
anverso de la puerta. Esta acción se da en pares, es decir, cada dos cuerdas (Fig. 15). Esta técnica presenta una variante que consiste en el trenzado agarrando cada 3 carrizos, esto se presenta en la zona D1 (Fig. 16)

- Técnica 3: Consiste en la unión de dos cuerdas formando una especie de «gancho» o "eslabón» (Fig. 17). Es posible que se esté usando esta técnica para «reparar» la puerta, ya que al romperse por la mitad algunos carrizos, y al no cambiarle ni quitarle, se está tratando de componer apretando y uniendo los espacios dejados por estos.

Las cuerdas que se entrelazan con los carrizos según la Técnica 2, presentan una variante como ya se mencionó, esto se debe a que en la zona D1 existen 75 carrizos, y al ser impar el número de troncos, en algunos momentos tiene que agarra 3 carrizos para regularizar y poder seguir con la técnica que se está aplicando (Técnica 2), que es la que impera en la elaboración de la puerta. Sin embargo en las
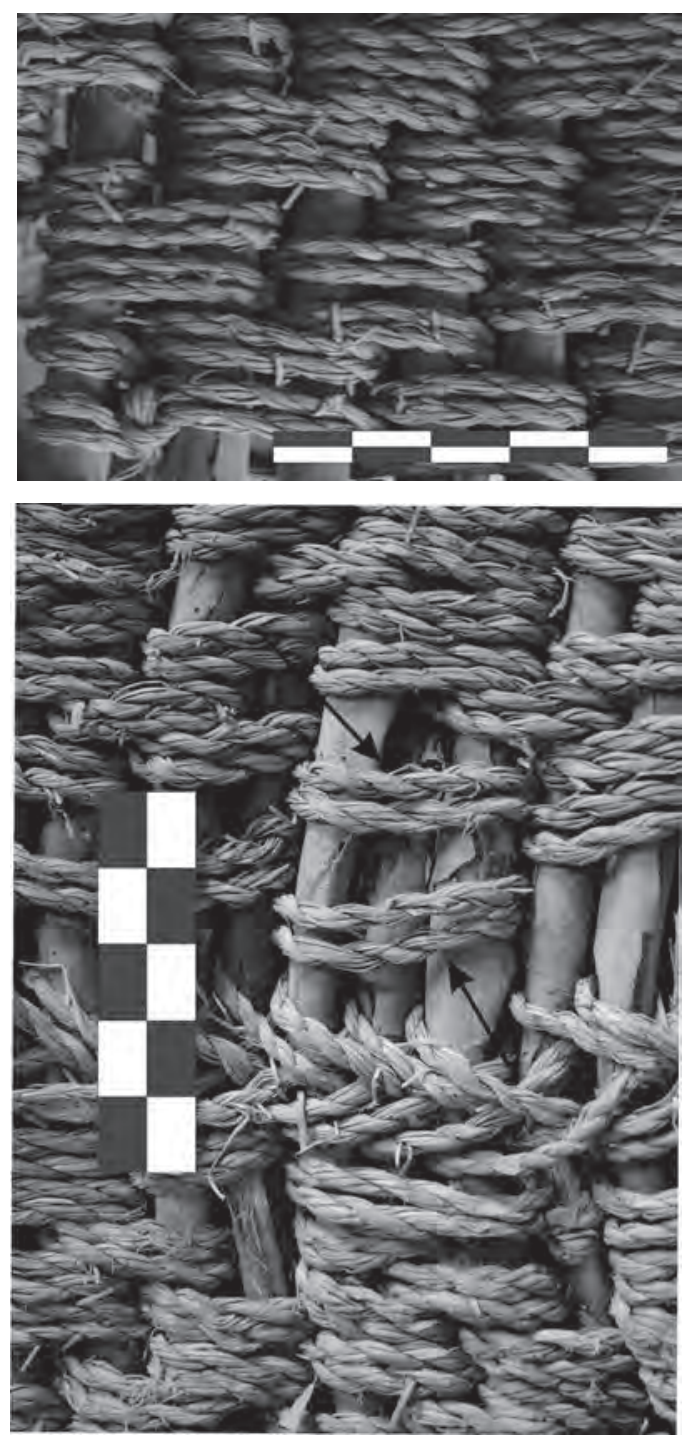

Figuras 15 y 16. Técnica 1, se puede notar el acabado en forma de "V". zonas A1, B1 y C1, esto no sucede, ya que en estas zonas solo existen 64 carrizos, debido que se fracturaron 11 carrizos.

El lado 1 es la cara que mira hacia la parte interna del recinto y se encuentra dispuesto hacia el sur (Fig. 6), presenta un mejor tratamiento en cuanto al trenzado, llegando incluso a servir una de las técnicas como diseño (Técnica 1).

En este lado de la puerta se puede ver también rastros de haber sido quemado, esto se puede notar en los bordes de las zonas A1 y B1 (Figs. 18 y 19), en donde, tanto la cuerda como el carrizo, han sufrido estos daños, es muy posible que esto sea resultado del mismo evento que incineró a los troncos donde se emplazaba la puerta.

El lado 2 es más tosca y tanto el sistema de soporte, como el de movilidad se ubican aquí. Presenta 5 troncos (de los cuales se conserva solo algunos pedazos), existentes, y uno inexistente (aún queda la evidencia donde se ubicó), a los que para un mejor estudio los numeramos (Fig. 13).

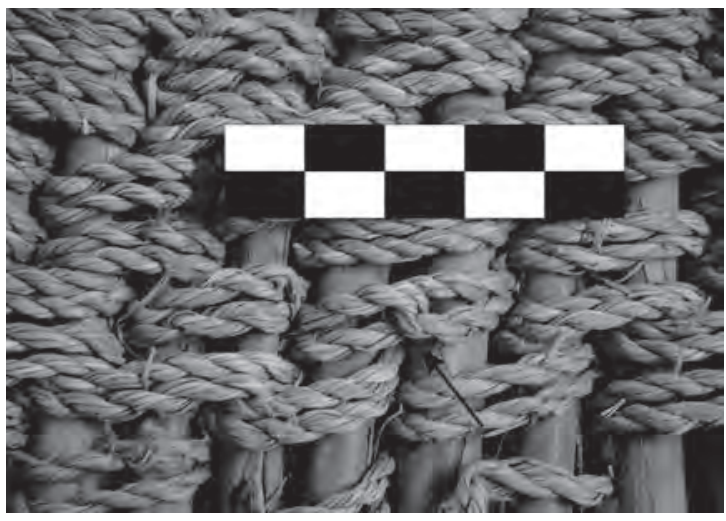

Figura 17. Técnica 3, la flecha indica su ubicación. 

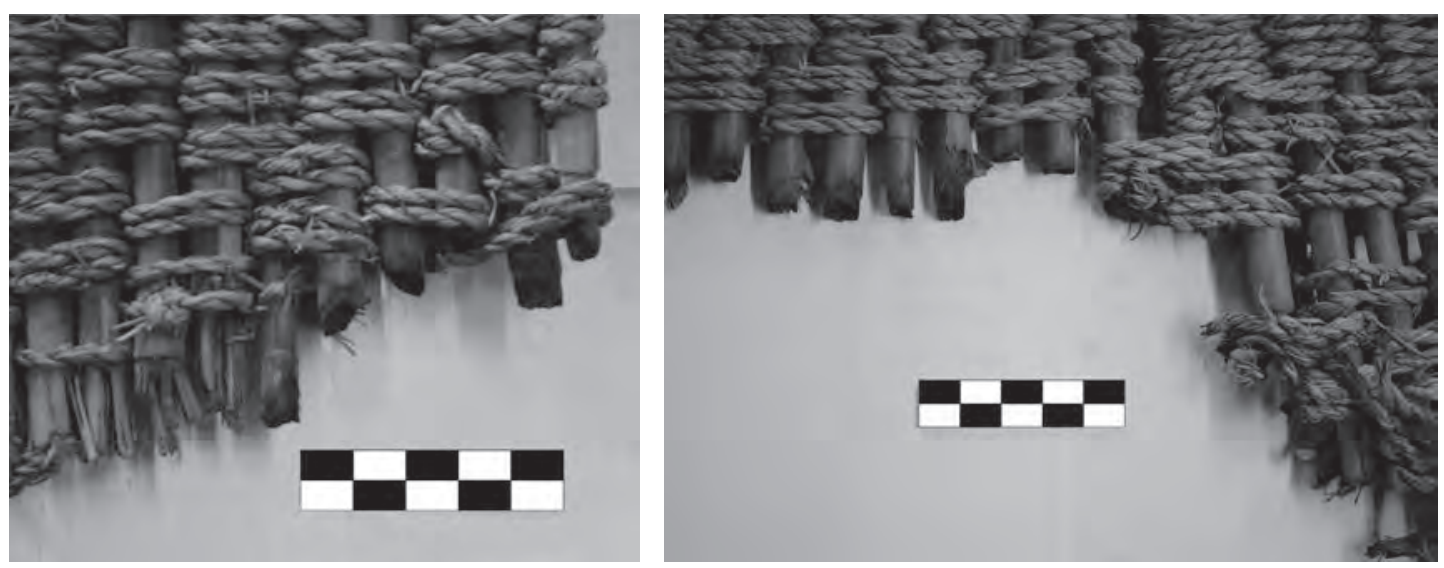

Figuras 18 y 19. Evidencia de quema en las zonas A1 y B1 respectivamente.

- Tronco 1: Presenta un tamaño de 1,75 m de largo por $7 \mathrm{~cm}$ de ancho, y se encuentra partido en dos pedazos. Forma parte del soporte del cuerpo de la puerta.

- Tronco 2: Presenta un tamaño de 1,96 m de largo por $5 \mathrm{~cm}$ de ancho, y se encuentra partido en cuatro pedazos. Forma parte del soporte del cuerpo de la puerta.

- Tronco 3: Presenta un tamaño de $98 \mathrm{~cm}$ de largo por $6 \mathrm{~cm}$ de ancho, y se encuentra solo la mitad del tronco. Forma parte del soporte del cuerpo de la puerta.

- Tronco 4: Este tronco no existe en la actualidad, sin embargo quedan las evidencias del amarre de las cuerdas donde se encontraba. Forma parte del soporte del cuerpo de la puerta.

- Tronco 5: Presenta un tamaño de $96 \mathrm{~cm}$ de largo por $10 \mathrm{~cm}$ de ancho, y solo se conserva la mitad del tronco. Se encuentra atado a los troncos 1 y 2 . Forma parte del soporte lateral de la puerta y es posible que se amarrara a uno de los soportes, funcionado a manera de bisagra.

- Tronco 6: Presenta un tamaño de $78 \mathrm{~cm}$ de largo por $10 \mathrm{~cm}$ de ancho, y solo se conserva una parte de este tronco. Se encuentra suelto, sin embargo queda rastros de haber estado amarrado con otros troncos, como en el caso del tronco 5. Forma parte del soporte lateral de la puerta. En uno de sus extremos tiene rastros de haber sido quemado (Fig. 20), esto es resultado del mismo evento que incineró a los troncos donde se emplazaba la puerta.

En este lado de la puerta se puede ver, al igual que en el lado 1, rastros de haber sido quemado, esto se puede notar en el anverso de los bordes de las zonas A1 y B1, en donde, tanto la cuerda como el carrizo, han sufrido estos daños, es muy posible que esto sea resultado del mismo evento que incineró a los troncos donde se emplazaba la puerta.

Gracias al hallazgo de la puerta in situ se ha podido determinar la posición original en la que funcionaba,

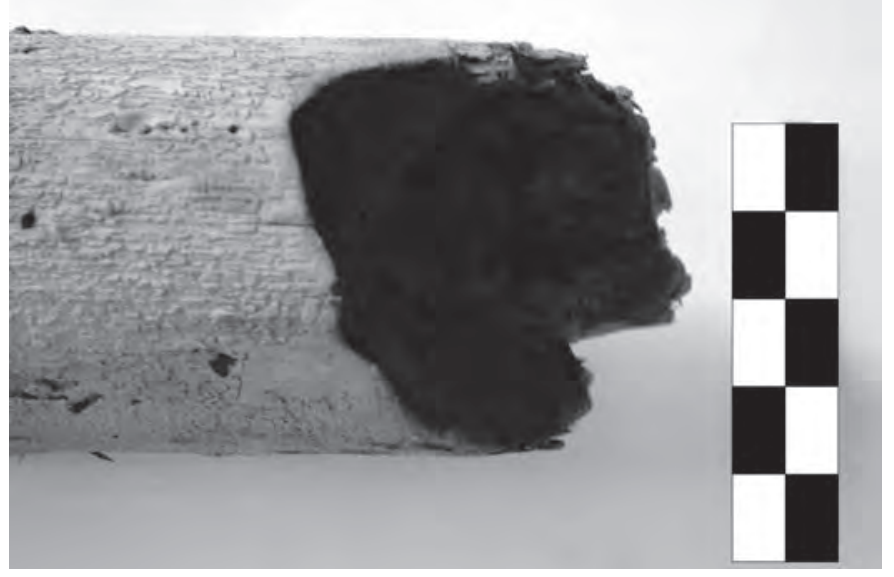


correspondiendo la parte de los carrizos sin tejido a la parte inferior, y los que terminan en tejido a la parte superior. Se pudo identificar también el sistema de movilidad que usaba para cerrar y abrirse, esta consistía en amarrar el tronco 5, al tronco (ubicados al oeste) donde se emplazaba la puerta, haciendo que se abra hacia el sur.

\section{RESUltAdOS}

Gracias a la investigación pudimos recrear el proceso de armado de la puerta de Potosí. Para realizar la soga, se agarró una porción junco (Scirpus sp.), y se torció hacia la izquierda (cuerda semipreparada), luego se dobló por la mitad y se unieron estas dos partes, torciendo hacia la misma dirección que el anterior (cuerda preparada) para darle más firmeza y fuerza. En total se construyeron 58 cuerdas que fueron unidas entre sí para formar una cuerda muy larga.

Se cortaron y prepararon 75 troncos de carrizo, que fueron dispuestos uno al costado del otro, para ser unidos mediante trenzado con la cuerda preparada previamente (Técnica 2). Este trenzado se realizó por secciones, ya que cada cierta distancia se colocó un tronco que se unió al cuerpo de la puerta, para esto se utilizó la técnica 1 . Al final de cada tronco se realizó un amarre cuadrado para unir los troncos del cuerpo de la puerta, con los troncos que servirían como soporte lateral. Este atado consiste en realizar un ballestrinque ${ }^{4}$ en uno de los postes y se le da vuelta a la cuerda de un lado a otro hasta que los troncos queden firmes y se asegura con otro ballestrinque (Figs. 21 y 22).

Esta puerta, ya armada, fue colocada en los postes emplazados en el vano del recinto, siendo amarrado el tronco 6 al tronco ubicado en la parte Este, para que sirviera como bisagra.

Es posible que la puerta sufriera una reparación en algún momento de su uso, la evidencia de este suceso se puede apreciar en 11 varas de carrizo fracturadas que se encuentran en las zonas D1 y D2. Al romperse los troncos de carrizo, se ajustaron con las cuerdas los espacios dejados por estos, para cerrar y unirlos, para ello se formó tres «bloques» de carrizos trenzados con la cuerda, que se están uniendo entre sí con la Técnica 3, estos se encuentran ubicados en la zona B1, producto de esta reparación se está formando una ondulación en la anatomía.

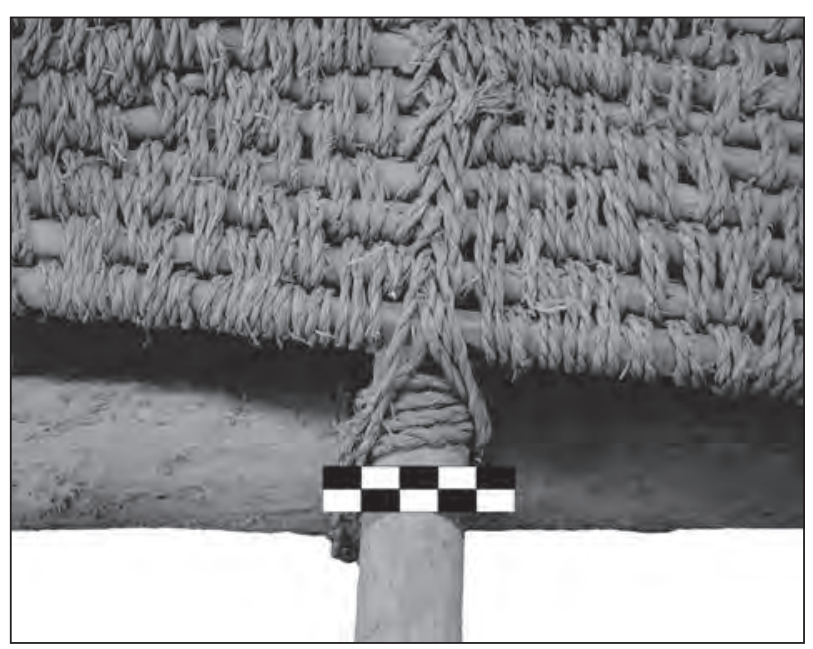

Figuras 21 y 22. Imagen de la cara y del anverso del amarre realizado para unir los troncos.

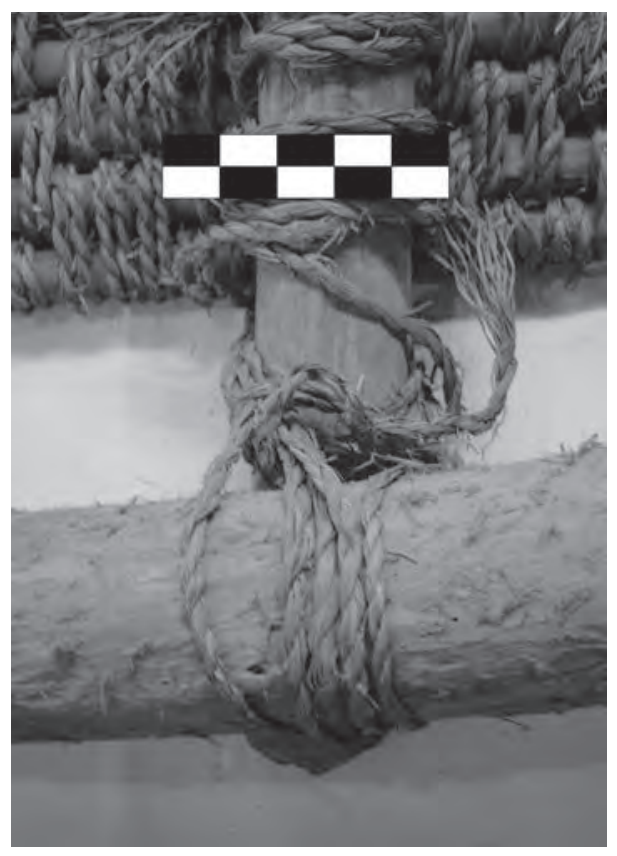




\section{Discusión}

El uso de la puerta en el Perú prehispánico ha sido un tema muy poco estudiado, una de las razones es la muy poca evidencia encontrada durante las excavaciones, ya que al ser de material orgánico, estas desaparecen producto de la humedad, clima y demás factores naturales, sin embargo existe evidencias indirectas o negativas, que nos hacen suponer la existencia de estos elementos arquitectónicos.

La escasa evidencia arqueológica que se tiene, consiste en postes donde estaban emplazadas, restos del mecanismo de movimiento en la jamba de los accesos, improntas dejadas por el movimiento de cierre y abertura, así como también las mismas puertas, como en el caso de Pachacamac, y de Potosí, que en el presente artículo lo estamos dando a conocer.

En 1911 el explorador norteamericano Hiram Bingham III puso en conocimiento mundial la ciudadela incaica de Machu Picchu, aquí descubrió, en un vanos de acceso principal al santuario, los restos de lo que al parecer fue un sistema de movimiento de una puerta (Fig. 23). Este sistema estaba compuesto por una piedra tallada en forma circular, con un agujero en el medio por el cual pasaba una cuerda, este elemento se ubicaba en el dintel del vano de acceso. Otro elemento de este sistema está compuesto por dos orificios rectangulares tallados en ambos lados de la jamba del vano, dentro de estos orificios se tallaron una especie de «columnas», una a cada lado, por donde pasaba una cuerda. Todos estos elementos servían como parte de una especie de «engranaje» que junto a un sistema de cuerdas y troncos permitían el movimiento de abertura y cierre de la puerta (Fig. 24).

Al respecto Bingham menciona: «[...] Sobre el macizo dintel se encuentra un ojo de amarra que se proyecta como para poder soportar una puerta colgante o una barra vertical. En el rincón del bloque más grande, en el pilar izquierdo de la puerta, se ha practicado un agujero para permitir la inserción de una clavija de piedra perpendicular. Le hemos llamado sujetador de barra; porque podría usarse para asegurar el extremo de una barra horizontal en l parte de atrás de la puerta. Un sujetador de barra correspondiente se encuentra en el lado derecho de la puerta. Los sujetadores en este caso se encuentran dispuestos en una depresión en forma de salseros practicadas en los bloques arriba y abajo.» (Bingham 1970: 107).
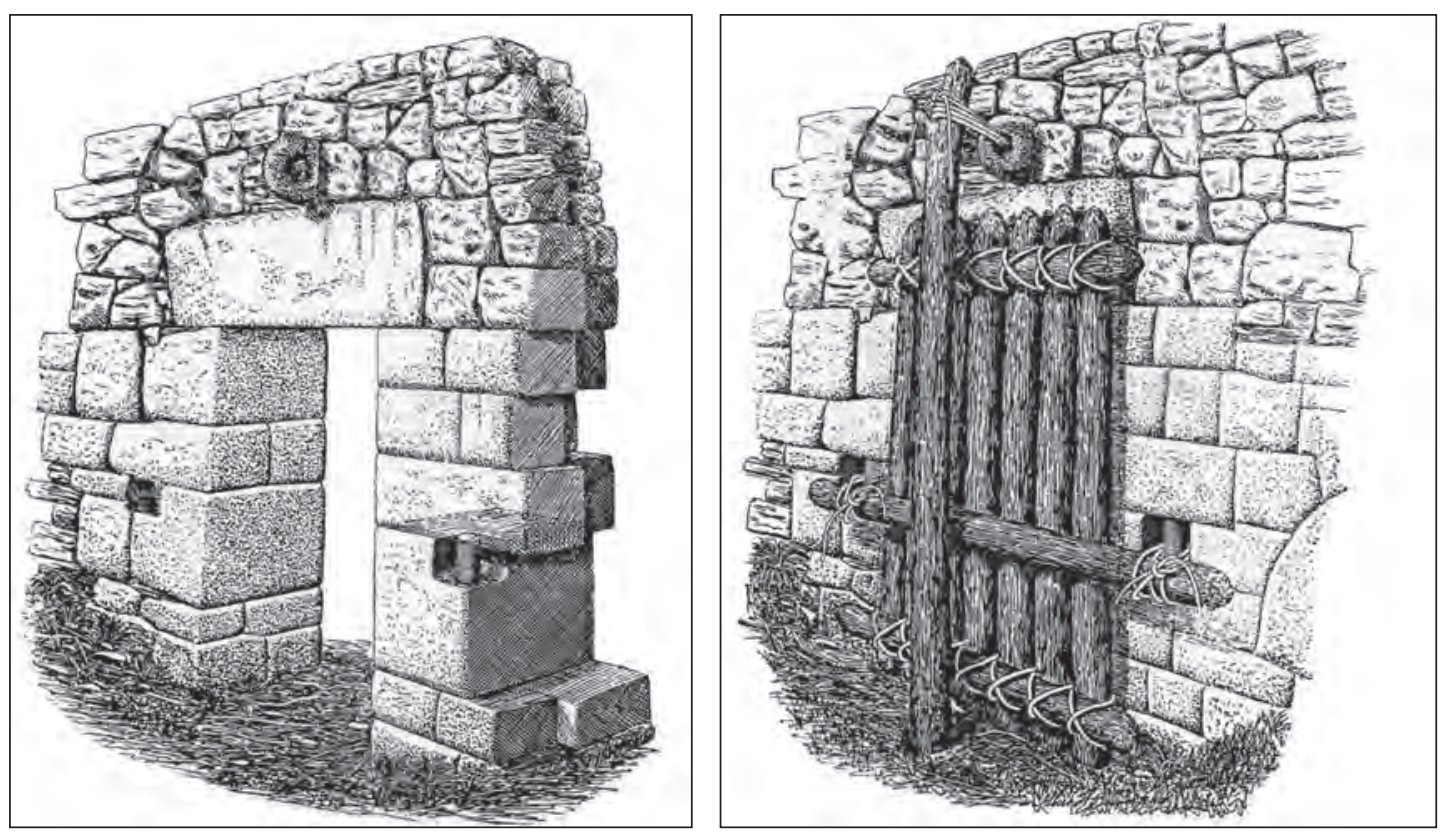

Figuras 23 y 24. Dibujo realizado por Hiram Bingham de la entrada principal al santuario de Machu Picchu y reconstrucción hipotética del sistema y la puerta. 
Esta evidencia, en el caso Inca y de la sierra, es muy pobre, a pesar de ello para el caso del departamento de Lima, las evidencias son un poco más ricas, una de las razones es la desecación de la tierra costeña que permite la conservación del material orgánico. Para el departamento de Lima tenemos el caso de la puerta de Pachacamac, que fue la primera puerta prehispánica encontrada en la costa central.

En 1938 Alberto Giesecke realizó excavaciones en el santuario de Pachacamac, con motivo de la VIII conferencia Interamericana. Giesecke realizó una limpieza a la estructura conocida como Templo pintado, fue aquí donde descubrió, entre los escombros de la parte superior o frontis del templo, una puerta hecha de carrizos y tela, con valvas de Spondylus princeps como decoración en una cara, y con improntas de aves y figuras geométricas en la otra; no existe un registro muy bueno de las excavaciones, por lo que no se puede tener mucho detalle de esta intervención. Posteriormente Francisco Vallejo realizó un análisis a esta puerta (Vallejo 2006) en donde lo describe como:

«La puerta de Pachacamac se compone de un armazón estructural a base de palos delgados en posición vertical, sujetos a su vez por amarras internas de hilos de algodón sobre los cuales se ha dispuestos dos paños de textil de algodón que cubren ambas caras o lados de la puerta [...] sus dimensiones son de $105 \mathrm{~cm}$ de largo por $75 \mathrm{~cm}$ de ancho, con un espesor promedio de $8 \mathrm{~cm}$ [...] la estructura interna se compone de al menos 47 palos delgados, ligeramente trabajados, pues se les ha retirado mayormente la corteza, sujetos a su vez por amarras transversales de hilos de algodón en una disposición sucesiva que enrolla o envuelve cada uno de estos palos y se conecta al siguiente en forma de "S». Estos hilos varían entre las tonalidades de marrón y blanco [...]» (Vallejo 2006: 93).

Vallejo llega a la conclusión, gracias al análisis iconográfico y de crónicas, que la puerta estudiada corresponde a la que se encontraba en el recinto del dios Pachacamac, siendo la cara externa la que presenta las valvas de Spondylus princeps, y la interna la que presenta las improntas, y es posible que perteneciera al periodo Intermedio Tardío (cultura Ychsma). A pesar de no haberse encontrado los muros estructurales del recinto, plantea que el sistema de movimiento era muy simple, ya que no presentaba un sistema de «engranaje», sino que por el contrario, es posible que la puerta presentara un madero vertical que se encontraba amarrado en la parte superior de esta y que sobresalía por los costados. Las partes sobresalientes del madero eran incrustadas sobre unos posibles agujeros ubicados en ambos lados de la jamba del vano de acceso (Fig. 25), esto nos lleva a entender que para mover la puerta se requería que una persona levantara y moviera la puerta hacia un costado para dejar pasar al visitante del oráculo.

Para el caso de la cultura Lima o del Intermedio Temprano, se tiene algunas evidencias del uso de puertas, especialmente para accesos a recintos restringidos o sagrados, como lo estamos viendo hasta el momento. Uno de estos casos se da en la Huaca Pucllana, el cual está compuesto por plataformas superpuestas, a las que se ingresaba desde la parte inferior hacia las zonas más restringidas por medio de rampas en forma de zigzag las cuales median más de cuatro metros de ancho. Es aquí, en la antesala de la rampa ceremonial o patio de la portada, en donde se encontraron postes con rastros de haber sido cortados y en mal estado de conservación, que aparentemente formarían el soporte de una puerta, así como también improntas en el piso dejadas por el movimiento de abertura y cierre de esta (Flores 2005).

En el Complejo Maranga también se halló evidencia de puertas, un claro ejemplo lo encontramos en Huaca San Marcos, esta es una pirámide compuesta por varias plataformas, tiene más de $300 \mathrm{~m}$ de largo, $100 \mathrm{~m}$ de ancho y $33 \mathrm{~m}$ de alto. Está conformada por adobitos hecho a mano, dispuestos en forma trapezoidal, y al igual que huaca Pucllana pertenece a la cultura Lima.

En 1967 se comenzaron las excavaciones en la plataforma 1 y 2 la cual estuvo a cargo del Dr. Luis Lumbreras, con el apoyo del entonces estudiante Pedro Alarcón como jefe de campo. La plataforma 1 es la más baja y es por donde se ingresa al espacio sagrado, es una amplia explanada rectangular, en el frente sur de dicha plataforma existe un pórtico con un vano de 2,62 $\mathrm{m}$ de ancho y una muralla 


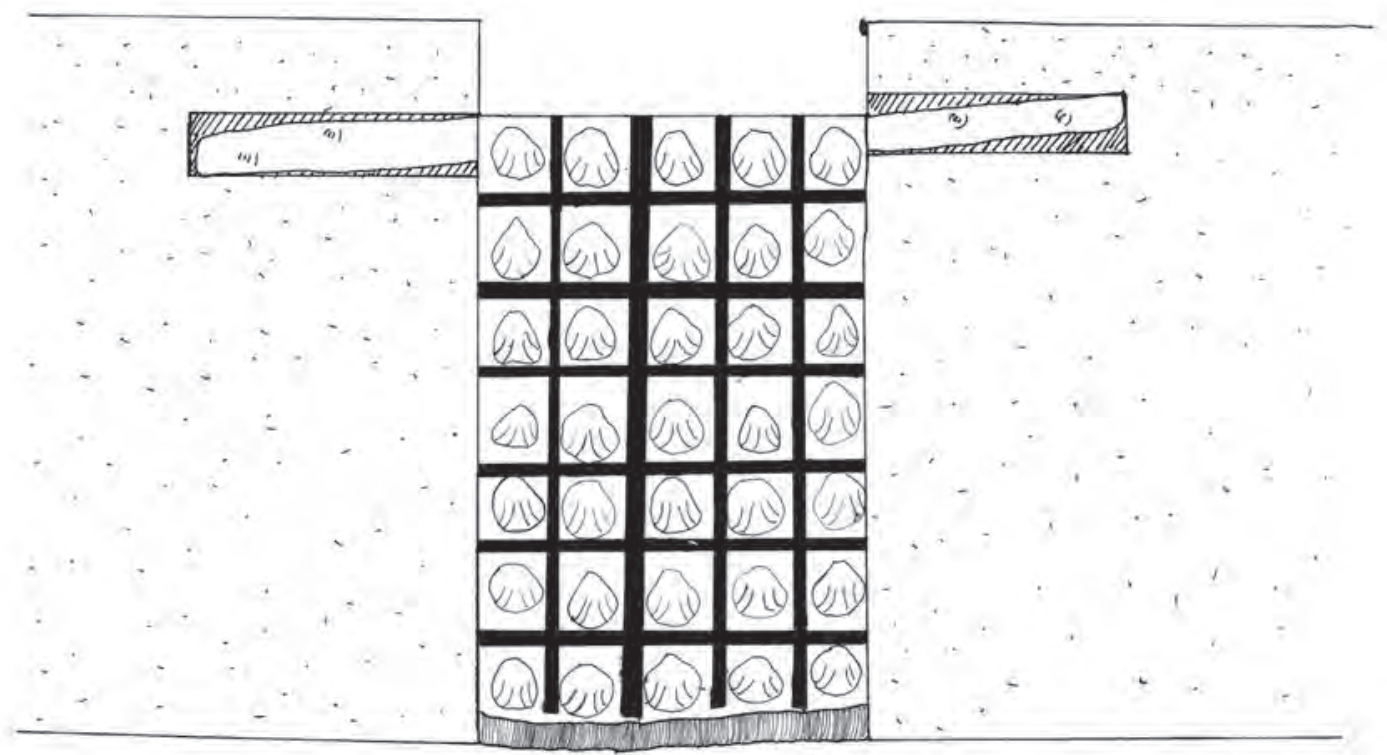

Figura 25. Reconstrucción hipotética de la puerta de Pachacamac realizada por Johnny Taira en base a la hipótesis planteada por Francisco Vallejo (2006).

triple de protección de 1,80 m de grosor, esta es una estructura laberíntica muy compleja que conduce desde la plataforma 1 a la cima de la plataforma 2, se va por una serie de pasadizos, rampas y escalinatas que en su recorrido van formando meandros entrelazados. El pórtico da paso a dos escalones que conducen hacia una galería muy angosta (Fig. 26), es aquí donde se descubrió un tronco de cerca de $20 \mathrm{~cm}$ de diámetro y unos $40 \mathrm{~cm}$ de altura que estaba destruido por fuego y cumplía la función de quicial (Lumbreras 2011).

Otro caso para el complejo Maranga es el descubrimiento in situ de una puerta hallado en el montículo 19 o Potosí. Esto se logró gracias a las excavaciones realizadas en el 2003 a cargo de la Lic. Carmen Gabe y Miguel Pazos, en la cual se excavaron las tres plataformas, siendo la tercera donde se halló una puerta con sus respetivos soportes, con rastros de quema y evidencia de todo un proceso ritual de clausura entorno al recinto que lo contenía.

La puerta se encontró asociada a un recinto cuadrangular pintado de amarillo u ocre, a la cual se accedía por medio de un pasadizo, por lo tanto, la puerta estaría sirviendo como división de ambos espacios, esta función de separación se realizó cuando esta se encontraba en funcionamiento (Fig. 27). Posteriormente el recinto fue clausurado, para ello se quemó tanto la puerta en su parte superior como los troncos que lo sostenían; se cortaron los soportes con el fin de ponerlos al nivel del recinto, se colocó varias ofrendas entre las que se encuentran unplato de fino acabado que contenía restos orgánicos y presentaba restos de hollín, colocados en la esquina de dos muros. También se halló una botella de cerámica que se ubicó debajo de la puerta, junto al poste y en la esquina de uno de los muros, esta cerámica presenta decoración de motivos lineales, geométricos y zoomorfos. Luego de todo el ritual de clausura se procedió a rellenar el recinto con adobitos hechos a mano colocados ordenadamente.

El funcionamiento de la puerta es posible gracias a un sistema de cuerdas y troncos que sirven a manera de «engranaje», que permitía el movimiento de abertura y cierre.

La cerámica encontrada en la capa asociada a la etapa de funcionamiento de la puerta (Fig. 28), se encuentra relacionada al estilo Lima y Maranga, lo que nos indica que la puerta fue construida durante el periodo Intermedio Temprano. Por otro lado, los Tiestos hallados en la capa asociada al 


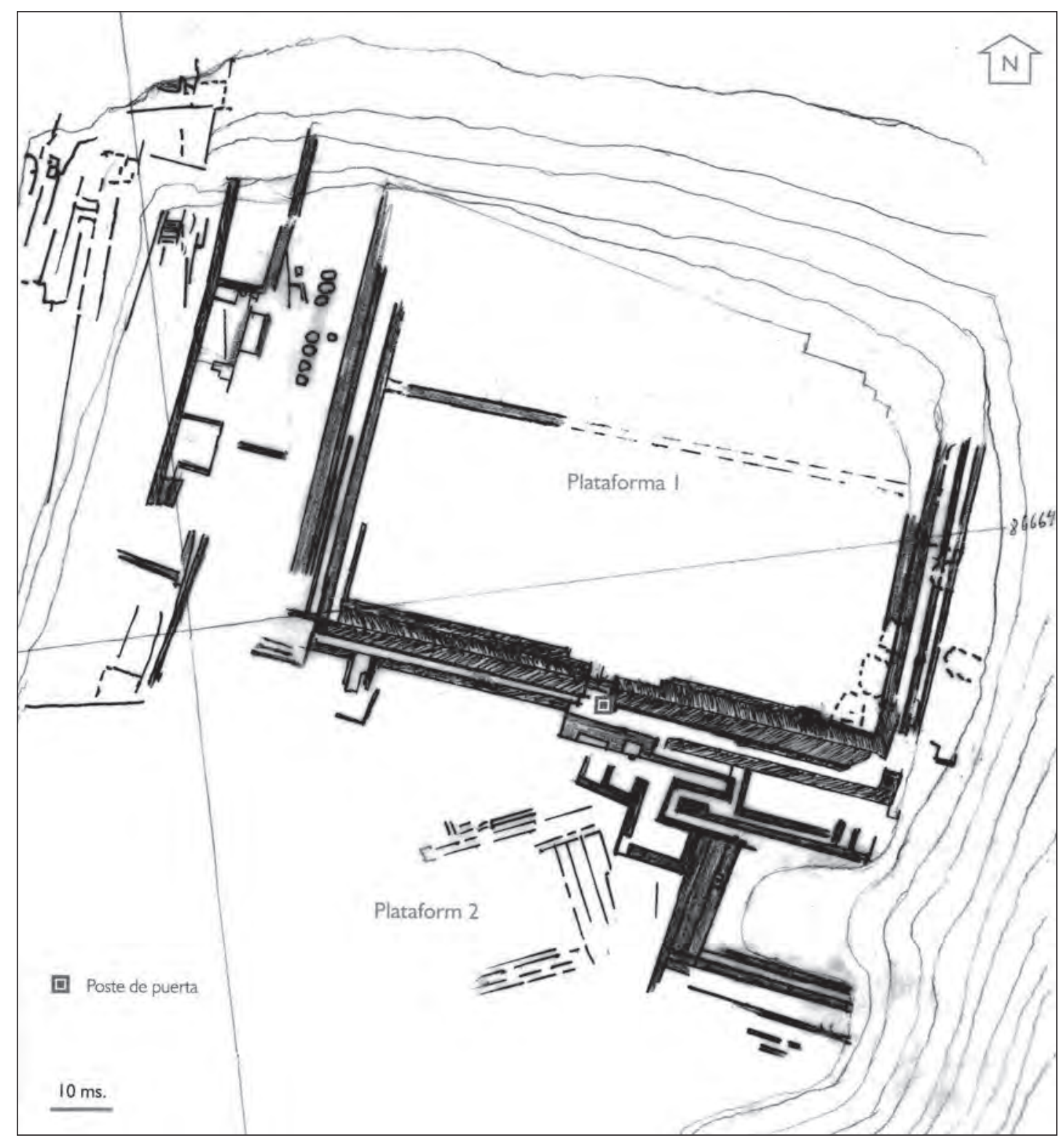

Figura 26. Plano de las plataformas I y II de la Huaca San Marcos, se puede apreciar donde se ubicó el poste (Lumbreras 2011).

proceso de clausura (Fig. 29), pertenecen a los estilos Maranga y Nievería, lo nos indican que la puerta se dejó de usar en el periodo Horizonte Medio, posiblemente como consecuencia de la invasión Wari en la costa central, suceso que llevó como consecuencia el abandono de centros religiosos y administrativos Lima.

La puerta como elemento arquitectónico no está presente en todos los recintos, al menos en los públicos. La utilización de la cerámica como maqueta para la construcción y planeamiento urbano no está muy planteada por el poco estudio que existe, sin embargo nos sirve como referencia gráfica de las construcciones prehispánicas. En estas representaciones el uso de la puerta como elemento arqui- 
Figura 27 Croquis del recinto y ubicación de la puerta de Potosí.

tectónico no esta presente en la mayoría de los casos, y en los que sí se presenta, están representadas individualmente o asociadas a lugares restringidos o sagrados, como en el caso de una cerámica de estilo Nievería presentada por Wolfgang Wurster, que reproduce el sistema de cierre de una puerta, así como la puerta misma (Wurster 1982) (Fig. 30).

Para el caso de Machu Picchu, la puerta se encuentra ubicada en la entrada principal al santuario, separando y protegiendo el sitio del exterior, es así que esta cumple una función de restricción y control de las personas que ingresan al santuario. Esta condición se repite en lugares como Pachacamac y Pucllana. En el primer caso la puerta está siendo utilizada para impedir la visión y el paso de cualquier sujeto común hacia el oráculo de Pachacamac; por otro lado, en Pucllana está sirviendo para controlar el paso de las personas a través de cada nivel de las plataformas, es decir cada puerta representa un nivel a su-

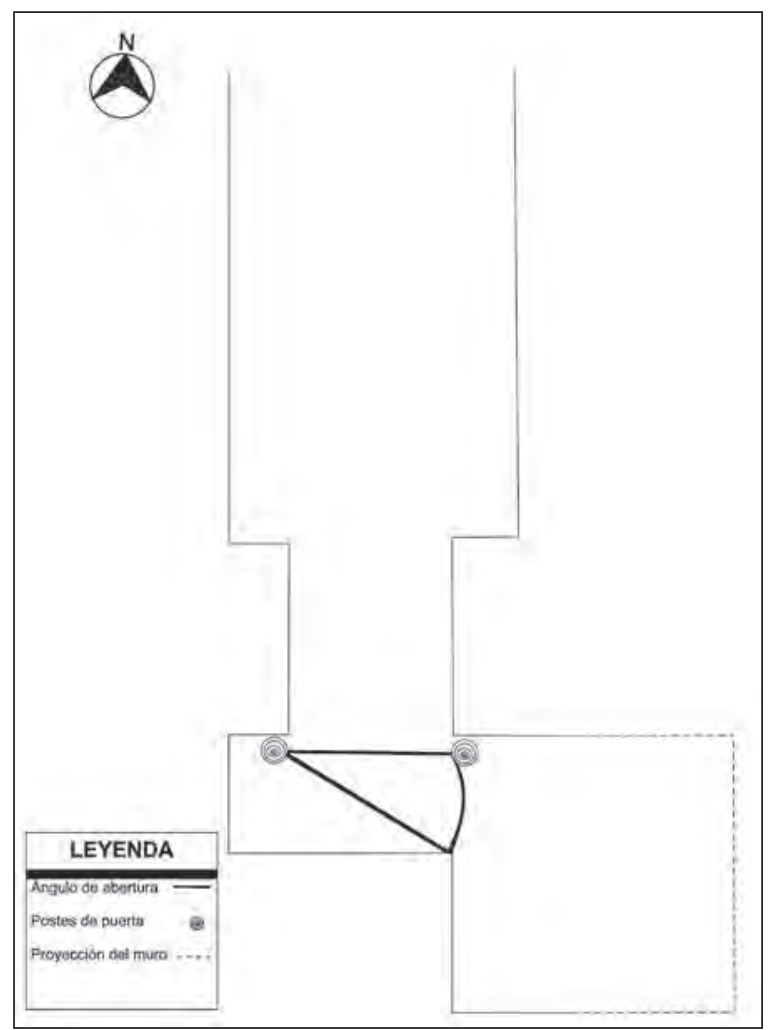

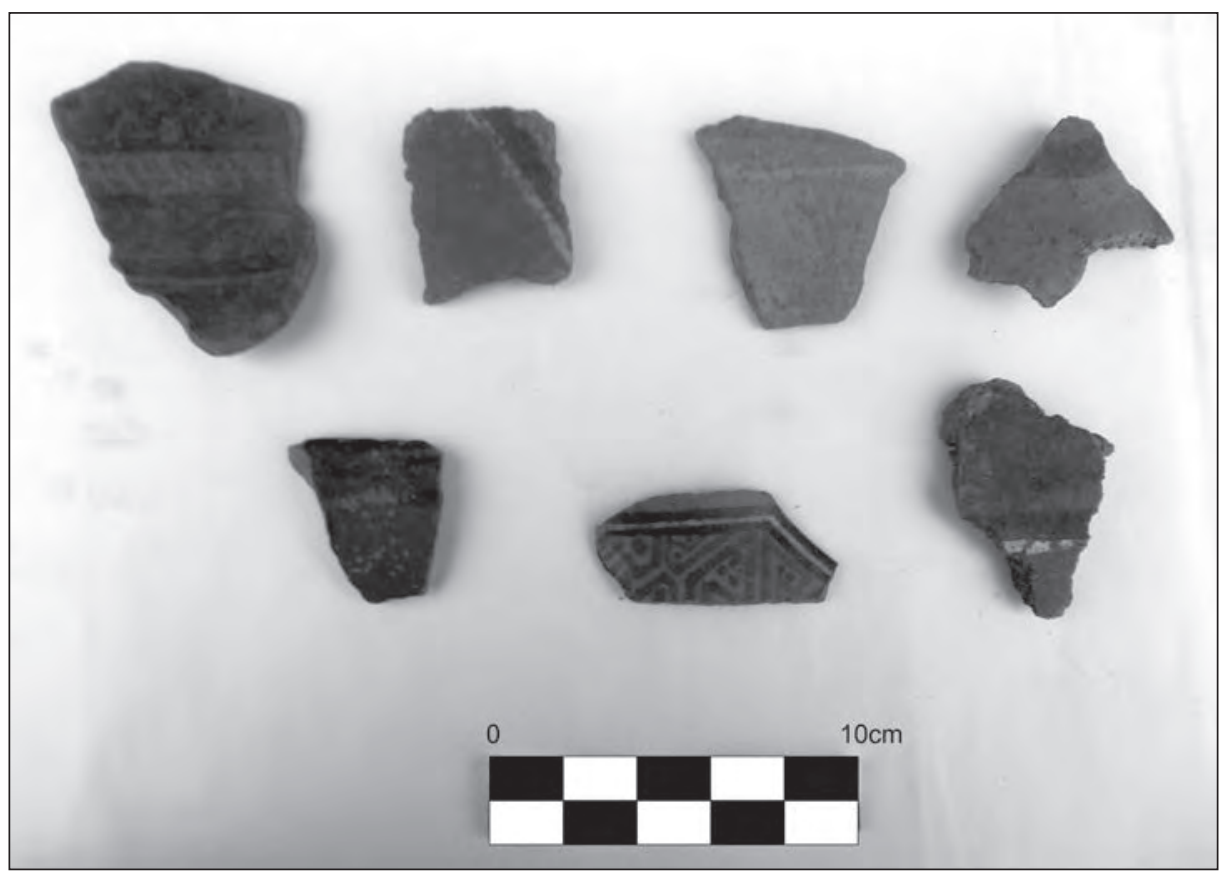

Figura 28. Cerámica de estilo Lima y Maranga hallada en la capa asociada al momento de funcionamiento de la puerta de Potosí. 


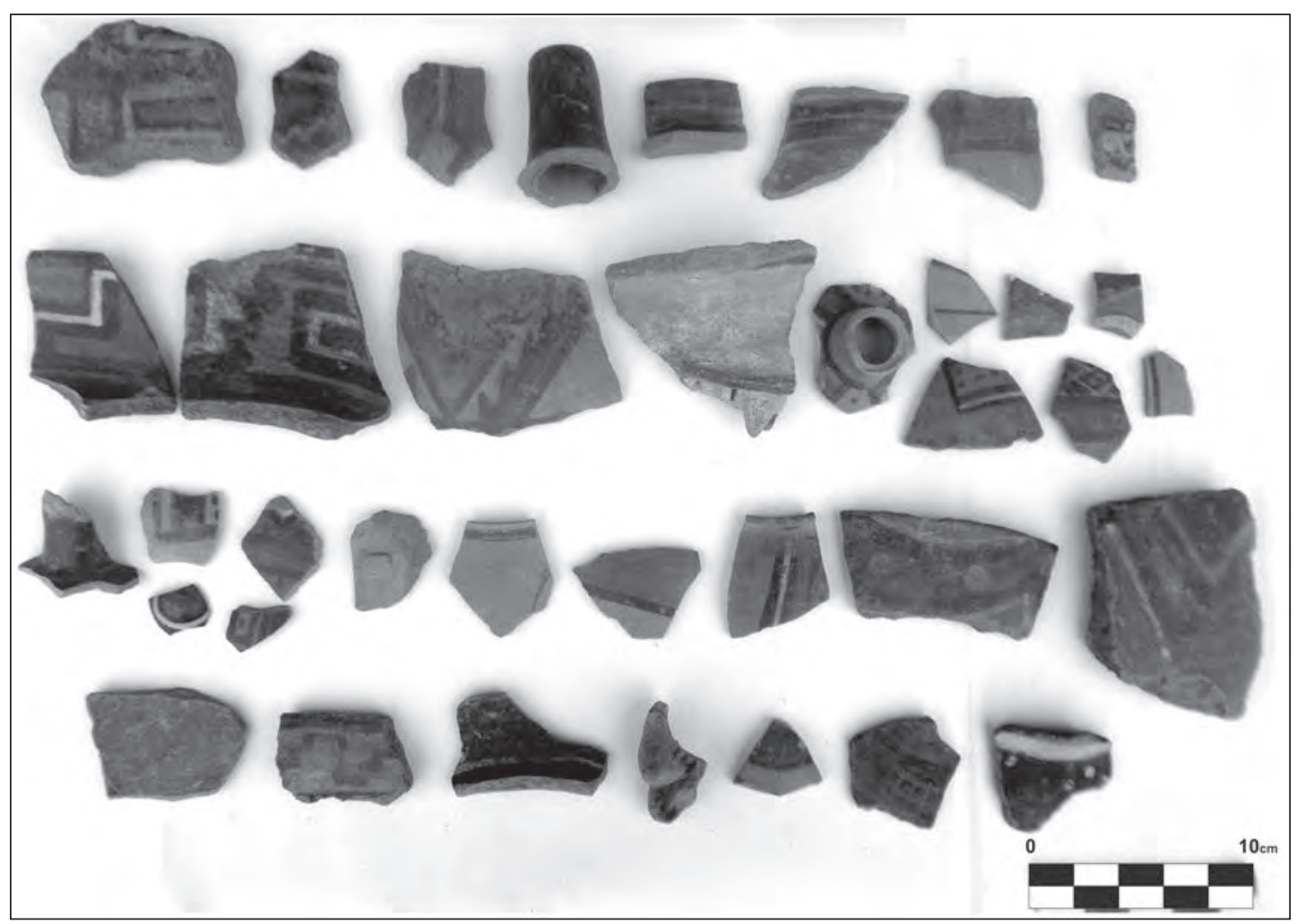

Figura 29. Cerámica de estilo Maranga y Nieveria hallada en la capa asociada al momento de clausura de la puerta de Potosí.

perar por el que viene a peregrinar, logrado solo al realizar previamente ciertos ritos y pagos.

Para Maranga estamos encontrando los casos de Huaca San Marcos y Potosí, ambos se encuentran ubicados y separando lugares sagrados o restringidos, con un tratamiento ritual al momento del abandono de la puerta. Para la Huaca San Marcos, esta evidencia solo se puede apreciar en los restos de quema y corte que se encuentran en el poste descubierto, sin embargo, el hallazgo de la puerta en Potosí nos debeló mucha información, ya que al encontrase in situ y casi sin alteraciones en el contexto, pudimos interpretar y analizar todo proceso ritual de sellado y clausura del recinto asociado, así como la importancia de la puerta como elemento arquitectónico, ya que existe todo un «ajuar» funerario en torno a este.

Figura 30. Dibujo a lápiz de la cerámica Nievería presentada por Wurster, documenta el sistema de cierre de una puerta (Lumbreras 2011:121).

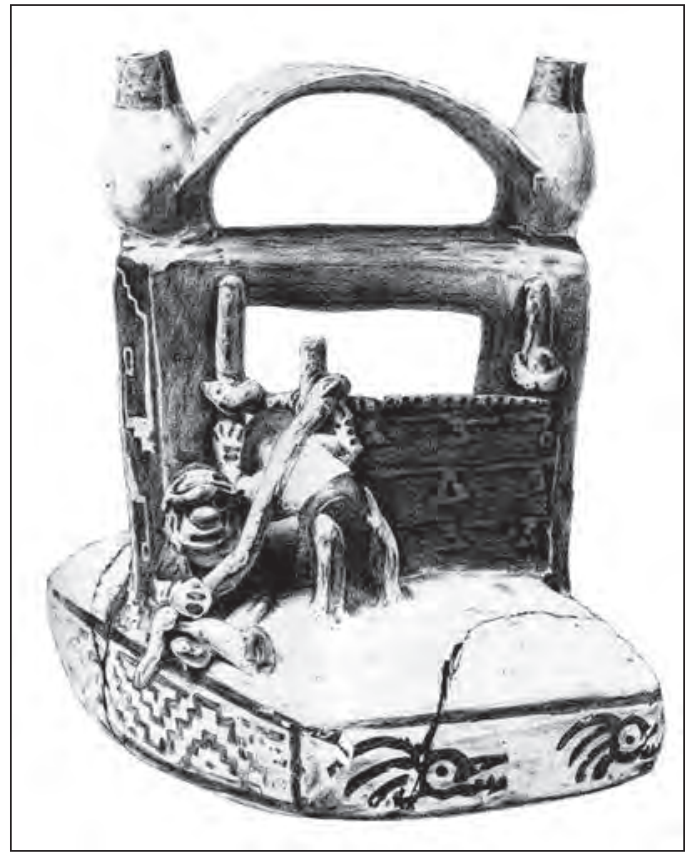


Por ello, planteamos como hipótesis, que el uso de las puertas como elemento arquitectónico está relacionado a lugares restringidos o sagrados, sirviendo como punto de control de las personas que ingresan hacia ciertos espacios, así como de separador entre un espacio privado, del público o de uno de menor «jerarquía»

En cuanto a la puerta de Potosí, la presencia de dos tipos de torsión en la soga, así como la gran cantidad de metros que se están utilizando, demuestra que su elaboración está relacionada al trabajo en conjunto de muchas personas, que tal vez, a manera de mita, están colaborando con cuerdas o mano de obra, como se hace en la actualidad para la construcción de puentes colgantes, como en el caso de Q'eswachaka, en la comunidad de Quehue, en Cusco.

Por otro lado, llama mucho la atención la forma de como ha sido reparada, ya que los carrizos rotos no fueron remplazados, ni construyeron otra para sustituir la deteriorada; esto nos puede indicar la importancia de esta, no solo como aspecto constructivo, sino material, ya que la puerta se convirtió en algo tan importante, como para no ser substituido, ni siquiera en sus piezas originales.

El funcionamiento de la puerta sucedió mediante un sistema de cuerdas y troncos que sirven a manera de «engranaje», esto permitía el movimiento de abertura y cierre. Ahora es posible saber un poco más sobre este sistema gracias al hallazgo de la puerta de Potosí, ya que presentaba todos estos elementos al momento de su descubrimiento.

El descubrimiento y posterior análisis de la puerta de Potosí nos significó un hito muy importante para el estudio y comprensión, de este elemento tanto a nivel arquitectónico como de su implicancia social en el espacio. Sin embargo quedan muchas dudas y preguntas por resolver, cuyas respuestas se podrán dar con estudios posteriores y que abarquen problemas y territorios mucho más amplios, puesto que la escasa evidencia no permite generalizar y llegar a un consenso, sino por el contrario solo a aproximaciones.

\section{CONCLUSIONES}

Presentamos las siguientes conclusiones obtenidas gracias al estudio y análisis de la puerta como elemento arquitectónico, y su implicancia social, así como sus asociaciones y todo el proceso ritual que estuvo en torno a esta.

1. El uso de las puertas como elemento arquitectónico está relacionado a lugares restringidos o sagrados, sirviendo como punto de control de las personas que ingresan hacia ciertos espacios, así como de separador entre un espacio privado, del público o de uno de menor «jerarquía». Esto se puede notar en las evidencias arqueológicas halladas en Huaca San Marcos, Pucllana, Machu Picchu, y especialmente en Potosí, en donde se encontró todo un proceso ritual de clausura en torno a dicho elemento arquitectónico.

2. El trabajo y el gran uso de material en la elaboración de la puerta de Potosí nos indican que se encuentra relacionada al trabajo en conjunto de muchas personas, que tal vez, a manera de mita, están colaborando con cuerdas o mano de obra, como se hace en la actualidad para la construcción de puentes colgantes en algunas comunidades andinas.

3. La forma de como ha sido reparada la puerta nos puede indicar la importancia de esta, no solo como aspecto constructivo, sino material, ya que la puerta se convirtió en algo tan importante, como para no ser substituida. Otro aspecto es el funcionamiento de la puerta, la cual es posible gracias a un sistema de cuerdas y troncos que sirven a manera de «engranaje», esto permitía el movimiento de abertura y cierre.

4. Por último, la etapa de funcionamiento de la puerta está relacionada al Intermedio Temprano, es decir, a la cultura Lima y Maranga, mientras que el abandono y clausura de esta se dio en el periodo Horizonte Medio, posiblemente como consecuencia de la invasión Wari en la costa central, suceso que llevó como consecuencia el abandono de centros religiosos y administrativos Lima. 


\section{Agradecimientos}

Queremos agradecer a la Lic. Carmen Gabe, directora del proyecto, quien nos concedió el permiso y apoyo para la investigación, así mismo a los arqueólogos Lic. Miguel Pazos, Lizardo Tavera y Pedro Vargas por la información brindada.

También expresamos nuestro agradecimiento a la arqueóloga Carol Verde por el análisis botánico de la puerta y al Dr. Alfredo Altamirano por la ayuda en la corrección y edición del artículo. Así como a los estudiantes de la Universidad Nacional Federico Villarreal: Joe Da Cruz, Renato Traverso y Rodrigo Macedo por su apoyo y colaboración en el proceso de análisis de la puerta.

\section{BibliografíA}

\section{ALARCÓN, Pedro}

1971 Tres fases técnico-constructivas en la huaca san Marcos. Tesis de Bachillerato en arqueología. Lima: UNMSM.

BELCORE, Martha

1970 «Ídolo de Cerámica encontrada en la Huaca dieciocho (Fundo Pando-Lima)». Boletín del Seminario de Arqueología PUCP 8: 159-160. Lima.

BINGHAM, Hiram

1913 «In the wonderland of Perú» The National Geographic Magazine N 4, Vol. XXIV.

1970 Machu Picchu. La ciudad perdida de los incas. Santiago: Zig-Zag.

CANZIANI, José

1987 «Análisis del complejo urbano Maranga-Chayavilca». Gaceta Arqueológica Andina 14: 10-17. Lima.

2008 Ciudad y Territorio en los Andes: Contribuciones a la historia del urbanismo prehispánico». Lima: PUCP.

CARRIÓN, Lucénida y Pedro ESPINOZA

2007a «Arquitectura, Cronología y función en la muralla 55E del complejo Arqueológico Maranga». Cuaderno de Investigaciones del Museo de sitio Ernst W. Middendorf 1: 33-66. Lima.

$2007 b$ «Investigaciones en la Huaca San Miguel, Complejo Arqueológico Maranga». Cuaderno de Investigaciones del Museo de sitio Ernst W. Middendorf 1: 67-115. Lima.

CCACHURA, Iván

2010 Secuencia de ocupación en el sitio Arqueológico № 18 del complejo urbano Maranga, en el valle bajo del río Rímac. Tesis de Licenciatura. Lima: UNFV.

ESPINOZA, Pedro

2010 «Arquitectura y procesos sociales tardíos en Maranga, valle bajo del Rímac, Lima». En: Arqueología en el Perú: Nuevos aportes para el estudio de las sociedades andinas prehispánicas; Editores Rubén Romero Velarde y Trine Pavel Svendsen, UNFV. Lima.

FERNÁNDEZ, Alejandro y Eric RODRÍGUEZ

2007 Etnobotánica del Perú Prehispánico. Trujillo: Ediciones Herbariun Truxillense.

FLORES, Isabel

2005 Pucllana: esplendor de la cultura Lima. Lima: INC.

FUNG, Rosa

2004 Quehaceres de la Arqueología Peruana. Lima: UNMSM

GABE, Carmen

2004 Informe del proyecto«Excavación con fines de consolidación, conservación, mantenimiento y Puesta en Valor en el Complejo Arqueológico Pando: Potosí, Miguel Grau, Aramburu. Distrito de San Miguel, provincia de Lima». Lima.

HUTCHINSON, Thomas

1873 Two years in Peru, with exploration of its antiquities. Londres: Sampson Low.

JAIME, Cecilia

1999 «Investigaciones en la huaca de San Marcos». Revista del Instituto de Investigaciones Histórico Sociales 3 (III): 65-91. Lima. 
JIJÓN Y CAAMAÑO, Jacinto

1949 Maranga. Contribuciones al conocimiento de los aborígenes del Valle del Rímac, Perú. Quito: La Prensa Católica.

KROEBER, Alfred

1954 «Proto-Lima. A middle Period culture of Perú». Fieldian a Anthropology 40(1): 1-125. Chicago.

LUMBRERAS, Luis

2011 Jacinto Jijón y Caamaño. Estudios sobre Lima prehispánica: Maranga. Quito: FONSAL.

MACK KAY, Martín y Rafael SANTA CRUZ

2000 «Las excavaciones del Proyecto Arqueológico huaca 20 (1999 y 2001)». Boletín de Arqueología PUCP 4: 583-595. Lima

MANRIQUE, Patricia

2011 «Arquitectura y contextos funerarios Lima en la laguna recreativa del Parque de las Leyendas». Boletín delMuseo de sitio Ernst W. Middendorf 10: 4-9. Lima.

2012 «Arquitectura y secuencia cultural prehispánica en huaca 43, Complejo Arqueológico Maranga» Boletín delMuseo de sitio Ernst W. Middendorf 11: 4-9. Lima.

MIDDENDORF, Ernst

1973 [1894] Perú. Observaciones y estudios del país y sus habitantes durante una permanecía de 25 años. Tomo II: La Costa. Lima: UNMSM.

NARVAEZ, Joaquín

1999 «Proyecto de investigaciones arqueológicas en la Huaca San Marcos. Resultados preliminares». Boletín del museo de Arqueología y Antropología 2(5): 5-10. Lima.

QUIROZ, Sonia

1992 «La Huaca Potosí Alto en el Complejo Arqueológico de Maranga».Pachacamac 1(1): 142-143. Lima.

ROSTWOROWSKI, María

1978 Señoríos indígenas de Lima y Canta. Lima: IEP.

SHADY, Ruth y Joaquín NARVÁEZ

1999 La Huaca San Marcos y la Antigua Ciudad de Maranga-Lima. Lima: UNMSM.

2000 Historia Prehispánica de Lima: Arqueología de la Huaca San Marcos. Lima: UNMSM.

SQUIER, Ephraim

1974 Un viaje por tierras incaicas: Crónica de una expedición arqueológica (1863-1865). Lima: UNMSM.

TELLO, Julio

1999 Arqueología del valle de Lima. Cuadernos de investigación del archivo Tello 1. UNMSM. Lima.

VALLEJO, Francisco

2006 «Análisis arqueológico de la puerta existente en la cámara del ídolo de Pachacamac». Wiñay Yachay 10: 90-104. Lima.

VILLAR CÓRDOBA, Pedro

1935 Arqueología del Departamento de Lima. Lima: Municipalidad de Lima. Lima.

WURSTER, Wolfgang

1982 «Modelos arquitectónicos peruanos: Ensayos de Interpretación». Revista del Museo Nacional XLVI: 253-266. Lima. 